\title{
Effect of del B drift on the H-mode power threshold in upper single null plasmas with ITER-like tungsten divertor on EAST
}

Chen, L.; Xu, G. S.; Yan, Ning; Nielsen, A. H.; Liu, J. B.; Gao, W.; Chen, R.; Qu, H.; Ding, F.; Mao, H. M. Total number of authors:

29

Published in:

Physics of Plasmas

Link to article, DOI:

$10.1063 / 1.5033983$

Publication date:

2018

Document Version

Publisher's PDF, also known as Version of record

Link back to DTU Orbit

Citation (APA):

Chen, L., Xu, G. S., Yan, N., Nielsen, A. H., Liu, J. B., Gao, W., Chen, R., Qu, H., Ding, F., Mao, H. M., Sun, Z., Zhang, L., Li, M. H., Zhang, W., Hu, G. H., Shao, L. M., Wu, X. Q., Du, H. F., Xu, J. C., ... Team, EAST. (2018). Effect of del $\mathrm{B}$ drift on the $\mathrm{H}$-mode power threshold in upper single null plasmas with ITER-like tungsten divertor on EAST. Physics of Plasmas, 25(7), [072504]. https://doi.org/10.1063/1.5033983

\section{General rights}

Copyright and moral rights for the publications made accessible in the public portal are retained by the authors and/or other copyright owners and it is a condition of accessing publications that users recognise and abide by the legal requirements associated with these rights.

- Users may download and print one copy of any publication from the public portal for the purpose of private study or research.

- You may not further distribute the material or use it for any profit-making activity or commercial gain

- You may freely distribute the URL identifying the publication in the public portal 


\section{Effect of $\nabla B$ drift on the H-mode power threshold in upper single null plasmas with ITER-like tungsten divertor on EAST}

L. Chen, G. S. Xu, N. Yan, A. H. Nielsen, J. B. Liu, W. Gao, R. Chen, H. Qu, F. Ding, H. M. Mao, Z. Sun, L. Zhang, M. H. Li, W. Zhang, G. H. Hu, L. M. Shao, X. Q. Wu, H. F. Du, J. C. Xu, Y. L. Li, N. Zhao, H. Lan, Y. Ye, H. Zhang, H. Q. Wang, S. Y. Ding, L. Wang, B. N. Wan, and EAST Team

Citation: Physics of Plasmas 25, 072504 (2018); doi: 10.1063/1.5033983

View online: https://doi.org/10.1063/1.5033983

View Table of Contents: http://aip.scitation.org/toc/php/25/7

Published by the American Institute of Physics

\section{Articles you may be interested in}

$\mathrm{H}$-mode access and the role of spectral shift with electrode biasing in the TCABR tokamak

Physics of Plasmas 25, 072301 (2018); 10.1063/1.5029561

Characteristics of the SOL turbulence structure in the first experimental campaign on W7-X with limiter configuration

Physics of Plasmas 25, 072502 (2018); 10.1063/1.5033353

Filamentary velocity scaling validation in the TCV tokamak

Physics of Plasmas 25, 072506 (2018); 10.1063/1.5038019

Hot spots induced by LHCD in the shadow of antenna limiters in the EAST tokamak

Physics of Plasmas 25, 082503 (2018); 10.1063/1.5019255

Kinetic theory of transport driven current in centrally fuelled plasmas

Physics of Plasmas 25, 072503 (2018); 10.1063/1.5030536

Comparative study of Fisch-Boozer and Ohkawa current drive mechanisms for electron cyclotron waves

Physics of Plasmas 25, 072501 (2018); 10.1063/1.5027609

\section{PHYSICS TODAY}

MANAGER'S GUIDE

WHITEPAPERS

\section{READ NOW}

PRESENTED BY

Accelerate R\&D with Multiphysics Simulation

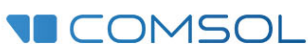




\title{
Effect of $\nabla B$ drift on the H-mode power threshold in upper single null plasmas with ITER-like tungsten divertor on EAST
}

\author{
L. Chen, ${ }^{1}$ G. S. Xu, ${ }^{1,2, a)}$ N. Yan, ${ }^{1, a)}$ A. H. Nielsen, ${ }^{3}$ J. B. Liu, ${ }^{1}$ W. Gao, ${ }^{1}$ R. Chen, ${ }^{1}$ H. Qu, ${ }^{1}$ \\ F. Ding, ${ }^{1}$ H. M. Mao, ${ }^{1}$ Z. Sun, ${ }^{1}$ L. Zhang, ${ }^{1}$ M. H. Li, ${ }^{1}$ W. Zhang, ${ }^{1}$ G. H. Hu, ${ }^{1}$ L. M. Shao, ${ }^{1}$ \\ X. Q. Wu, ${ }^{1}$ H. F. Du, ${ }^{1}$ J. C. Xu, ${ }^{1}$ Y. L. Li,${ }^{1}$ N. Zhao, ${ }^{1}$ H. Lan, ${ }^{1}$ Y. Ye, ${ }^{1}$ H. Zhang,,${ }^{1}$ H. Q. Wang, ${ }^{1}$ \\ S. Y. Ding, ${ }^{1}$ L. Wang, ${ }^{1,4}$ B. N. Wan, ${ }^{1}$ and EAST Team ${ }^{1}$ \\ ${ }^{1}$ Institute of Plasma Physics, Chinese Academy of Sciences, Hefei 230031, China \\ ${ }^{2}$ University of Science and Technology of China, Hefei 230026, China \\ ${ }^{3}$ Department of Physics, Technical University of Denmark, Fysikvej, DK-2800 Kgs.-Lyngby, Denmark \\ ${ }^{4}$ School of Physics and Optoelectronic Technology, Dalian University of Technology, Dalian 116024, China
}

(Received 8 April 2018; accepted 21 June 2018; published online 10 July 2018)

\begin{abstract}
In this paper, we will experimentally investigate the power threshold $\left(P_{\mathrm{L}-\mathrm{H}}\right)$ in upper single null plasmas with an ITER-like tungsten divertor under different $\nabla B$ drift directions on EAST [F. Ding et al., Commissioning and PSI Behavior of the ITER-Like W/Cu Divertor in EAST 22nd PSI, Rome (2016)]. The power threshold for the low $(\mathrm{L})$ to high $(\mathrm{H})$ confinement mode has a clear and positive toroidal magnetic field, $B_{\mathrm{T}}$, dependence when the $\nabla B$ drift points toward the primary Xpoint $(B \times \nabla B \uparrow)$. A factor of 2-3 increase in $P_{\mathrm{L}-\mathrm{H}}$ is observed for the $\nabla B$ drift away from the primary X-point $(B \times \nabla B \downarrow)$. The edge and core impurities quantified by spectroscopy measurements show comparable levels for the transitions for both drift directions. On the other hand, it is found that the divertor $\mathrm{D} \alpha$ emission just prior to the L-H transition is lower for $B \times \nabla B \uparrow$, compared with that for $B \times \nabla B \downarrow$. The upper in-out divertor asymmetry, as manifested by particle fluxes measured by the divertor triple Langmuir probe, is most marked for $B \times \nabla B \downarrow$, and with significantly more particle flux to the outer divertor. The reversing field increases the particle flux into the upper inner and lower outer divertor, reducing the in-out asymmetry. One important distinction between the two field directions has been observed, with respect to the amplitude of the scrape-off layer (SOL) parallel flow. A dedicated experiment under similar target plasma conditions shows a lower SOL density and thus a steeper density gradient slightly inside the separatrix, where a lower $P_{\mathrm{L}-\mathrm{H}}$ is found for the $B \times \nabla B \uparrow$, compared to that for $B \times \nabla B \downarrow$. We, therefore, conclude that the fielddependent SOL plasma conditions play an important role in the transition physics. Published by AIP Publishing. https://doi.org/10.1063/1.5033983
\end{abstract}

\section{INTRODUCTION}

The baseline operational scenario for ITER will be the high-confinement mode (H-mode) with the type-I edge localized mode (ELM). ${ }^{1}$ As ITER will initially operate only slightly above the predicted threshold power, a deeper understanding of the physics behind the transition dynamics is required. $^{2}$ The International Tokamak Physics Activity (ITPA) threshold scaling is $P_{\text {scal }}=0.0488\left\langle n_{\mathrm{e}}\right\rangle^{0.72} B_{\mathrm{T}}{ }^{0.80} S^{0.94}$ [MW], where $\left\langle n_{\mathrm{e}}\right\rangle$ is the central line-averaged electron density in $10^{20} \mathrm{~m}^{-3}, B_{\mathrm{T}}$ is the toroidal magnetic field in $\mathrm{T}$, and $S$ is the plasma surface area in $\mathrm{m}^{2}{ }^{3}$ Other factors may affect the transition, e.g., a radial electric field in the edge region, $E_{\mathrm{r}}{ }^{4}$ zonal flow, ${ }^{5}$ neutral density, ${ }^{6}$ and wall material. ${ }^{7,8}$ In JET, ${ }^{7}$ ASDEX-Upgrade, ${ }^{8}$ and EAST, ${ }^{9}$ a reduction of power threshold $\left(P_{\mathrm{L}-\mathrm{H}}\right)$ in the metal first wall is observed, compared with that in the carbon wall. It has been observed since the discovery of the H-mode in ASDEX that the ion $\nabla B$ drift has a large influence on the $P_{\mathrm{L}-\mathrm{H} \cdot}{ }^{10}$ This effect is substantial for DIII-D, ${ }^{11}$ Alcator C-Mod, ${ }^{12,13} \mathrm{NSTX}^{14}$ and MAST, ${ }^{15}$ where factors of 2-3 increase in $P_{\mathrm{L}-\mathrm{H}}$ are demonstrated when the ion $\nabla B$ drifts away from the primary X-point. Attempts have been made to explain this based on neo-classical ion cross-field fluxes

\footnotetext{
${ }^{\text {a)} E l e c t r o n i c ~ a d d r e s s e s: ~ g s x u @ i p p . a c . c n ~ a n d ~ y a n n i n g @ i p p . a c . c n ~}$
}

driven by the poloidal temperature gradient in the scrape-off layer (SOL). ${ }^{16}$ However, it has been found in DIII-D that the edge ion temperature gradients are the same in both upper and lower single null configurations [upper single null (USN) and lower single null (LSN)], pointing to the role of poloidal velocity flow shear. ${ }^{11}$ Previous experiments on Alcator CMod have shown that the parallel flow, which couples to the core toroidal rotation, depends strongly on the magnetic configuration and may have an important effect on the transition. ${ }^{12}$ Recent measurements using gas puff imaging inside the separatrix for LSN plasmas have shown that nonlinear transfer from turbulence to zonal flow is stronger in the favorable configuration than it is in the unfavorable one. ${ }^{17}$ All these results show that the ion $\nabla B$ drift effect has its origin at the SOL and/or inside the separatrix. In contrast, it exhibits a similar or even lower $P_{\mathrm{L}-\mathrm{H}}$ with the ion $\nabla B$ drift away from the primary X-point in $\mathrm{JET}^{18}$ and $\mathrm{EAST}^{9}$ under all carbon walls or divertors, but the cause for this remains elusive. In order to minimize the power required to access to the H-mode for ITER, more research studies are needed to evaluate the influence of the ion $\nabla B$ drift on $P_{\mathrm{L}-\mathrm{H}}$ in a tokamak with an ITERlike metal wall.

This paper will focus on the effect of the $\nabla B$ drift on $P_{\mathrm{L}-\mathrm{H}}$. Dedicated experiments in USN plasmas with an ITER-like 
tungsten divertor were performed on the EAST tokamak with attention on the edge plasma conditions just before the L-H transitions. We obtain a significantly lower power threshold for a $\nabla B$ drift towards the primary X-point, consistent with the lower recycling regime. For the $\nabla B$ drift away from the primary X-point, we typically observe a factor of 2-3 times larger power threshold.

The paper is organized as follows: Sec. II presents the experimental setup and a brief description of the experiments. The recent results in the L-H power threshold experiments with respect to the $\nabla B$ drift direction in the 2016 experimental campaign are described in Sec. III. Section IV addresses the edge plasma conditions at the L-H transition for the two field directions. Summary and discussion are presented in Sec. V.

\section{EXPERIMENTAL SETUP}

EAST has been technically upgraded with an advanced divertor configuration and heating scheme similar to ITER. ${ }^{19}$ The machine can be flexibly operated in single null (SN) and double null (DN) divertor configurations. Here, we only focus on the upper single null (USN) discharges. The heating systems have been upgraded, including two lower hybrid wave (LHW) systems (4 MW, $2.45 \mathrm{GHz}$ and $6 \mathrm{MW}$, $4.6 \mathrm{GHz}$ ); an ion cyclotron resonance frequency (ICRF, $6 \mathrm{MW}$ each) heating system; co- and counter-current neutral beam injection (NBI, $4 \mathrm{MW}$ each) systems; and an electron cyclotron resonance heating (ECRH, 1 MW) system. The upgraded heating systems provide sufficient power steps to minimize the error of the L-H transition power threshold values. The plasma facing components (PFCs) are converted into the metal wall step by step. EAST has been equipped with the molybdenum first wall, a carbon lower divertor and an ITER-like monoblock tungsten divertor, as well as a newly installed cryopump which significantly enhances the particle exhaust and capacity of recycling control in H-mode discharges, as shown in Fig. 1.

In the 2016 campaign, experiments were performed on the EAST tokamak with plasma current $I_{\mathrm{P}}=0.4 \mathrm{MA}$, toroidal field $B_{\mathrm{T}}=2.5 \mathrm{~T}$, and matched divertor configuration and line-averaged electron density $\left\langle n_{\mathrm{e}}\right\rangle$ of $2.6-3.6 \times 10^{19} \mathrm{~m}^{-3}$. The discharges were conducted under the lithium-coated wall conditioning. Initial attempts to accomplish wall conditioning involved siliconization by glow discharge, and the resultant L-H power threshold was comparable with that in the lithium-coated wall. Note that before the application of lithium- or silicon-wall coating, no H-mode can be achieved due to the bad wall condition and radio frequency (RF) power coupling $\left(P_{\text {loss }} \geq 1 \mathrm{MW}\right)$, suggesting the power threshold is reduced under wall conditioning. Instead, our experiment was completed after several hundreds of discharges, where 6-12 $\mathrm{g}$ of lithium was evaporated daily for 1-2 $\mathrm{h}$ using three ovens at different toroidal midplane positions. This has been proved to effectively enhance the uniformity of lithium coverage $\sim 94 \%$ of the wall (the surface area of EAST is approximately $60 \mathrm{~m}^{2}$ ). During the 2016 campaign, a level of $\sim 250 \mathrm{~g}$ of lithium was used in total. Approximately, a $7.0 \mu \mathrm{m}$ thick lithium film $\left(0.534 \mathrm{~g} \mathrm{~cm}^{-3}\right.$,

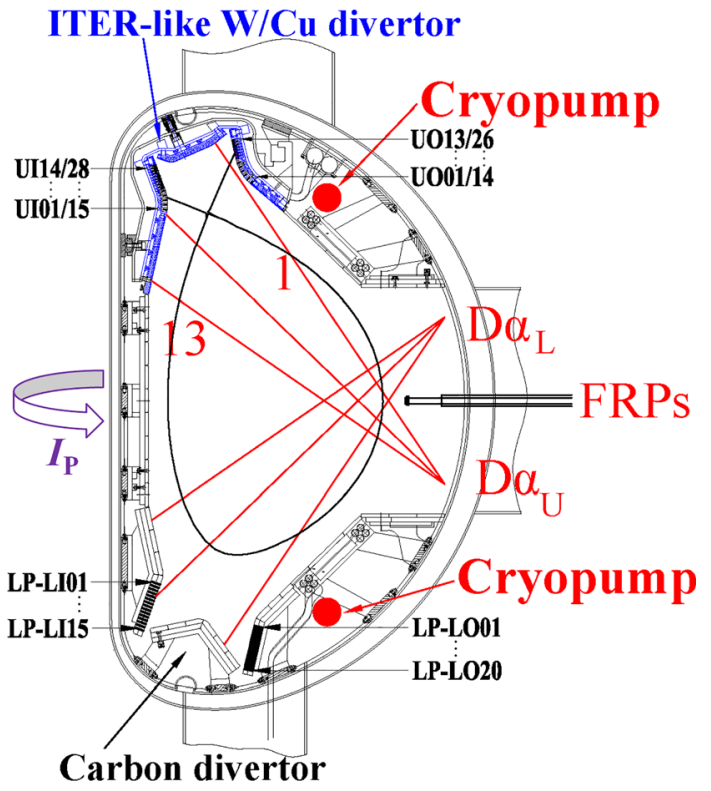

FIG. 1. Poloidal cross section of EAST showing some diagnostics: $\mathrm{D} \alpha$-Balmer-alpha emission of deuterium, Langmuir probe arrays on the divertor targets and fast reciprocating probes, with up and down cryopumps underneath the outer divertor target plates.

$300 \mathrm{~K}$ ) was deposited on the wall, as directly evidenced by the laser-induced breakdown spectroscopy system measurement. ${ }^{20}$ At this level of wall conditioning, no obvious change in the L-H power threshold can be observed with respect to lithium accumulation in this experiment. This result is in agreement with the previous experiments, ${ }^{21}$ where strong effects on the $\mathrm{L}-\mathrm{H}$ power threshold have been observed in the $\mathrm{Mo} / \mathrm{C}$ wall due to heavy lithium-wall coating, over $800 \mathrm{~g}$. The experiment in the effect of the $\nabla B$ drift direction on the L-H transition was carried out under comparable levels ( $\sim 200 \mathrm{~g}$ ) of lithium conditioning, as also evidenced by the similar intensity level of line emission from lithium (see Fig. $6)$. The L-H power threshold comparison was conducted under the USN configuration and the change of sign for the $\nabla B$ drift was achieved by changing the direction of the toroidal magnetic field. The plasma current $I_{\mathrm{P}}$ is in the anticlockwise direction viewing from the top, as shown in Figs. 1 and 13. In this study, the L-H transitions are identified by the sudden drop of divertor $\mathrm{D} \alpha$ emission measured by a photodiode array and the increase in the line-averaged electron density $\left\langle n_{\mathrm{e}}\right\rangle$, as well as the stored energy. The SOL parallel flow is measured by Mach probe arrays fixed on the fast reciprocating probe system (FPRs) of the low field side (LFS) midplane, and also evaluated by the divertor Langmuir probes (LP). The sign convention used here is that flow directed along the toroidal magnetic field direction is assigned a positive value. The lines of sight of the diagnostics are also shown in Fig. 1.

In this article, discharges were operated in deuterium with divertor configurations and all the L-H transitions in the plot occurred during the plasma flat top. The net power across through separatrix at the L-H transition, $P_{\text {loss }}$, is calculated as, $P_{\text {loss }}=P_{\text {aux }}+P_{\text {ohmic }}-\mathrm{d} W / \mathrm{dt}$, with $P_{\text {aux }}$ being the absorbed auxiliary heating power in which possible losses and absorption coefficients are taken into account, from 
either solely heating by the lower hybrid (LH) wave, or combined power from radio frequency (RF) heating and neutral beam injection (NBI), $P_{\text {ohmic }}$ the Ohmic power, and $\mathrm{d} W / \mathrm{dt}$ the change rate of the stored energy. The net power loss, $P_{\text {net }}$ $=P_{\text {loss }}-P_{\text {rad }}$, may be more appropriate to quantify the $\mathrm{H}$ mode power threshold. Upon examination, typical radiation power before the L-H transitions is $\sim 80-350 \mathrm{~kW}$ and it is not considered in this paper. For $\nabla B$ drift towards the primary X-point, a low input power level is used, which reduces the uncertainties due to a low $\mathrm{d} W / \mathrm{dt}$ contribution. However, for $\nabla B$ drift away from the primary X-point, the $\mathrm{d} W / \mathrm{dt}$ contribution will be larger, as a combined heating scheme of $\mathrm{RF}$ and NBI was used. The calculation of absorption power for LHW and ICRF is similar to previous analyses on EAST. ${ }^{21}$ The analysis of the NBI power absorption has been performed using the guiding center code ORBIT and NUBEAM/TRANSP. ${ }^{22}$ Furthermore, the ECRH power has been injected using the standard second harmonic scheme which provides pure electron heating with $80 \%$ absorption of a source power below $0.5 \mathrm{MW} .{ }^{23}$ All global parameters are averaged over a time interval of $10 \mathrm{~ms}$ in the L-mode phase just before the time of the $\mathrm{L}-\mathrm{H}$ transition, as will be shown in Sec. III.

\section{H-MODE POWER THRESHOLD IN USN PLASMAS}

\section{A. Effects of the $\nabla B$ drift direction}

The $\nabla B$ drift direction exhibits a significant influence on the access to H-modes. ${ }^{9-18,21}$ However, the underlying physics mechanism is still unclear. Dedicated experiments were performed with matched plasma shapes and $I_{\mathrm{P}} / B_{\mathrm{T}}$ pairs in upper single null (USN) plasmas in EAST with the ITER-like tungsten divertor. Figure 2 shows the effect of the $\nabla B$ drift direction on the access to H-modes with the lower hybrid current driven (LHCD) for the USN configuration for two field directions under similar target plasma conditions. The injected LHCD power with a frequency at $4.6 \mathrm{GHz}, \mathrm{P}_{\mathrm{LH} 1}$, was kept the same for the two field directions. As can be seen, the H-mode is achieved with LHCD under the USN divertor configuration with the $\nabla B$ drift towards the primary X-point (shot $65041, B \times \nabla B \uparrow$ ), as further evidenced by the appearance of ELMs, as seen in the outer divertor $\mathrm{D} \alpha$ emission. The H-L transition occurs after the ELM events, then the L-H transition takes place subsequently, suggesting that the injected power is sufficient for $\mathrm{H}$-mode access at such plasma conditions. In contrast, for USN with the $\nabla B$ drift away from the primary X-point
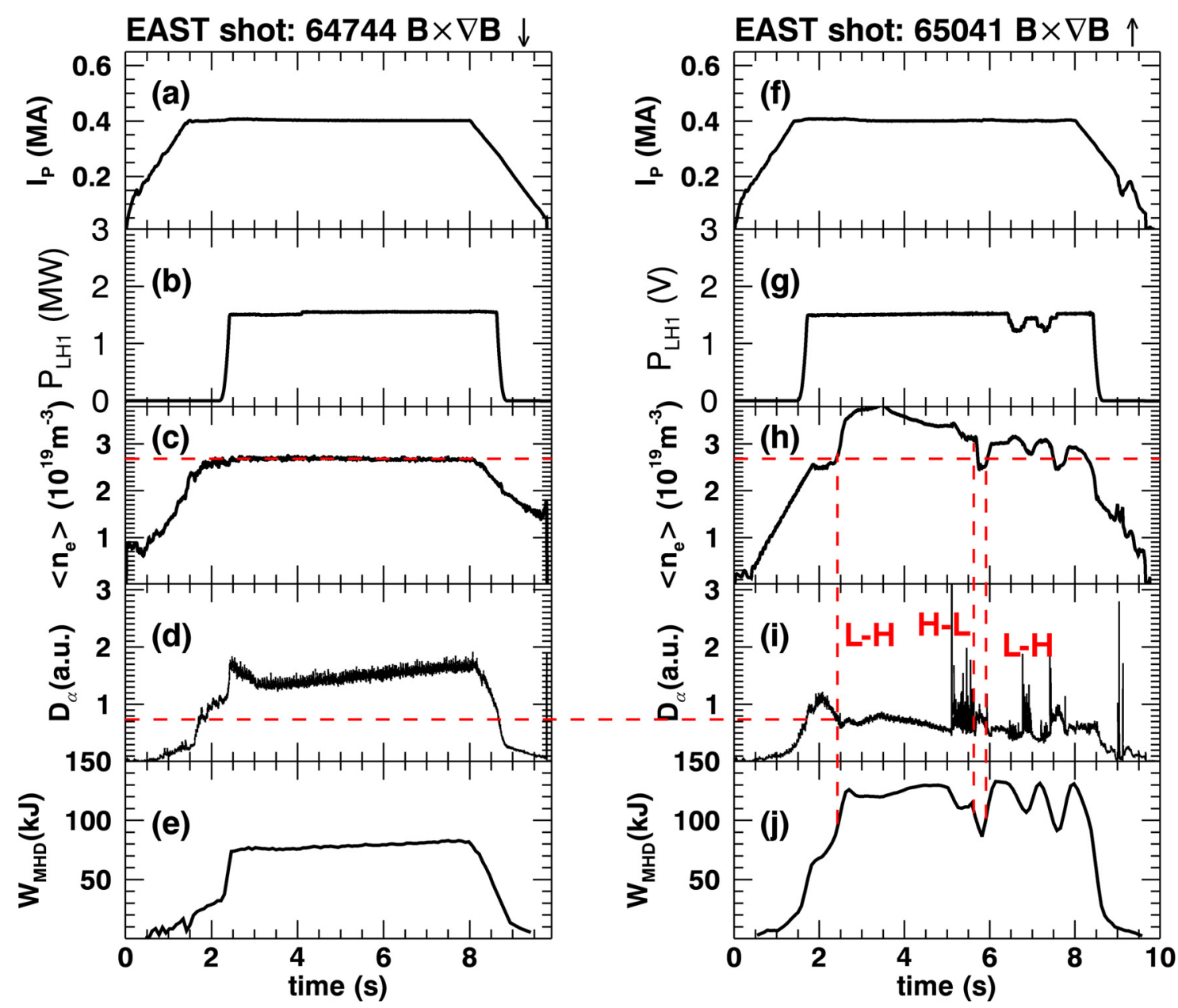

FIG. 2. Two shots run in the USN configuration with the $\nabla B$ drift away $(B \times \nabla B \downarrow)$ and towards $(B \times \nabla B \uparrow)$ the primary X-point at similar plasma conditions: (a) and (f) plasma current, (b) and (g) heating power provided by the low hybrid wave, (c) and (h) line-averaged electron density, (d) and (i) outer divertor D $\alpha$ emission, and (e) and (j) stored energy calculated by EFIT. Multiple L-H transitions occurred at the $\nabla B$ drift toward the primary X-point, whereas no transitions occurred for the other side drift direction. 
(shot $64744, B \times \nabla B \downarrow$ ), the plasma remains in the L-mode with similar initial target plasma conditions. Hence, this suggests that the power needed for the $\mathrm{L}-\mathrm{H}$ transition, $P_{\mathrm{L}-\mathrm{H}}$, in EAST is lower with the $\nabla B$ drift towards the active divertor. Note that the $\mathrm{D} \alpha$ emission in the divertor region just prior to the L-H transition is much lower for USN for the $\nabla B$ drift towards the primary $\mathrm{X}$-point, compared with that for the $\nabla B$ drift away from the primary X-point, as indicated in Figs. 2(d) and 2(i). On the other hand, for the $\nabla B$ drift away from the primary $\mathrm{X}$-point, $\mathrm{H}$-modes were achieved when combining heating schemes, as shown in Fig. 3. As can be seen, the H-mode is achieved and maintained with combined radio frequency (RF) heating of two LHCD, ICRF, as well as ECRH (shot $62785, B \times \nabla B \downarrow$ ), as further evidenced by the appearance of ELMs. The density is near constant during the $\mathrm{H}$-mode phase. Or, the L-H transition can be achieved with combined LHCD and NBI (shot $62809, B \times \nabla B \downarrow)$, as evidenced by the sudden increase in line-averaged density $\left\langle n_{\mathrm{e}}\right\rangle$, followed by an H-L transition. Note that the plasma remains in the L-mode after the $\mathrm{H}-\mathrm{L}$ transition, suggesting that the injected power is marginal to the transition power threshold. As indicated in Figs. 2 and 3 , it is found that the L-H power threshold is lower for the $\nabla B$ drift towards the primary X-point, compared with that for the $\nabla B$ drift away from the primary X-point.

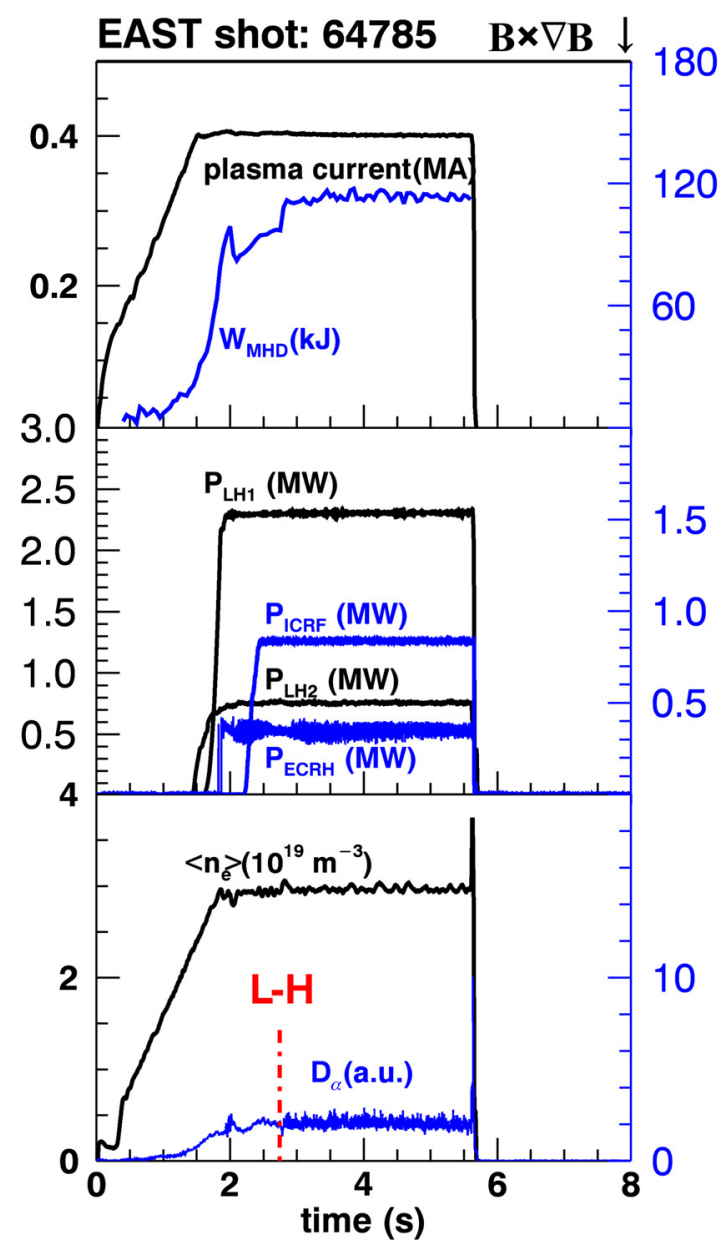

To further investigate the effect of the $\nabla B$ drift on the L-H transition and minimize the effects of plasma density on $P_{\mathrm{L}-\mathrm{H}}$, density scan experiments have been carried out in EAST for two toroidal magnetic field directions. Figure 4 shows such experiments with LHCD for USN at two field directions. The injected LHCD power is kept the same, while the reflected LH power, $P_{\mathrm{LHR}}$, is lower for the $B \times \nabla B \downarrow$, suggesting that the calculated $P_{\text {loss }}$ is slightly higher due to an increase in $P_{\text {aux }}$, compared with that for the $B \times \nabla B \uparrow$. As can be seen, the L-H transition is achieved at a line-averaged electron density $\left\langle n_{\mathrm{e}}\right\rangle \sim 2.8 \times 10^{19} \mathrm{~m}^{-3}$ for the $\nabla B$ drift towards the primary X-point (shot $65056, B \times \nabla B \uparrow$ ), as seen in the $\mathrm{D} \alpha$ emission. On the other hand, for USN with the $\nabla B$ drift away from the primary X-point (shot $64779, B \times \nabla B \downarrow$ ), no transition occurs. This demonstrates that the power threshold is lower for USN for the $\nabla B$ drift towards the primary X-point, compared with that for the $\nabla B$ drift away from the primary $\mathrm{X}$-point. Note that the $\mathrm{D} \alpha$ emission is also lower before the L-H transition at similar density for the $\nabla B$ drift towards the primary $\mathrm{X}$-point, which may suggest that the neutral density plays an import role in the L-H transition. Further investigations are given in Sec. IV. The divertor detachment is achieved at $\left\langle n_{\mathrm{e}}\right\rangle \sim 4 \times 10^{19} \mathrm{~m}^{-3}$ for both field directions, and detailed analysis of this will be reported elsewhere.

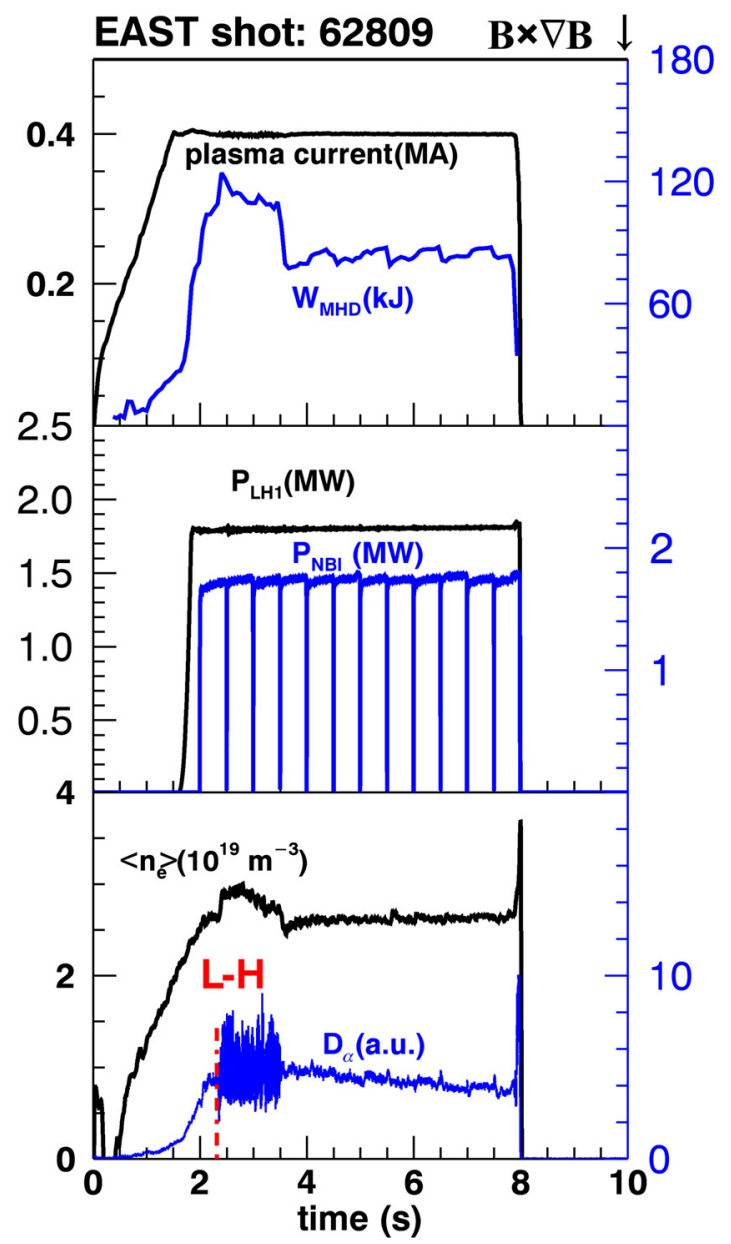

FIG. 3. For the $\nabla B$ drift away from the primary X-point $(B \times \nabla B \downarrow)$, transition can hardly be achieved by the solely heating scheme on EAST, i.e., low hybrid wave heating, ion cyclotron resonance frequency, electron cyclotron resonance frequency heating or neutral beam injection (NBI) due to limited source power. Only with cooperated radio frequency (RF) heating (shot 62785), or combined heating scheme by RF and NBI heating (shot 62809), did the transition occur. 
Following the density scan experiments, a statistical analysis of $P_{\mathrm{L}-\mathrm{H}}$ just prior to the L-H transition has been carried out at a density range of 2.6-3.6 $\times 10^{19} \mathrm{~m}^{-3}$, matched plasma shapes, and $I_{\mathrm{P}} / B_{\mathrm{T}}$ pairs $(0.4 \mathrm{MA} / 2.5 \mathrm{~T})$, as displayed in Fig. 5. The most remarkable result from this experiment is that $P_{\mathrm{L}-\mathrm{H}}$ is strongly reduced with the $\nabla B$ drift towards the primary X-point. This is shown in Fig. 5(a): $P_{\text {loss }}$ for $B \times \nabla B \uparrow$ (red circles) is significantly reduced by a factor of 2-3 relative to that for $B \times \nabla B \downarrow$ (cyan diamonds). The $P_{\mathrm{L}-\mathrm{H}}$ is only $\sim 50 \%$ of the threshold values predicted by the international tokamak scaling, ${ }^{3}$ as indicated by the dashed line. Note that there are a few shots with slightly overestimated $P_{\mathrm{L}-\mathrm{H}}$ for $B \times \nabla B \downarrow$, where the $\mathrm{L}-\mathrm{H}$ transition is achieved immediately after another additional power is injected upon the initial heating, as described previously in Fig. 3. On the other hand, edge plasma conditions, such as impurities levels, can also affect the L-H power threshold. This may be why the $P_{\text {loss }}$ scatters for the two field direction in the experiments. Here, an increase in the $P_{\mathrm{L}-\mathrm{H}}$ with increasing density is not clearly seen, which may due to the limited density range of 2.6-3.6 $\times 10^{19} \mathrm{~m}^{-3}$. The minimum density, below which an increase in $P_{\mathrm{L}-\mathrm{H}}$ can be observed, is around $2.8 \times 10^{19} \mathrm{~m}^{-3}$, as demonstrated in Fig. 4. In addition, the edge safety factor, $q_{95}$, and the plasma surface area, $S$, are about 7.0 and 39.0, respectively. The existence of the sawtooth has not been observed before the L-H transition at this

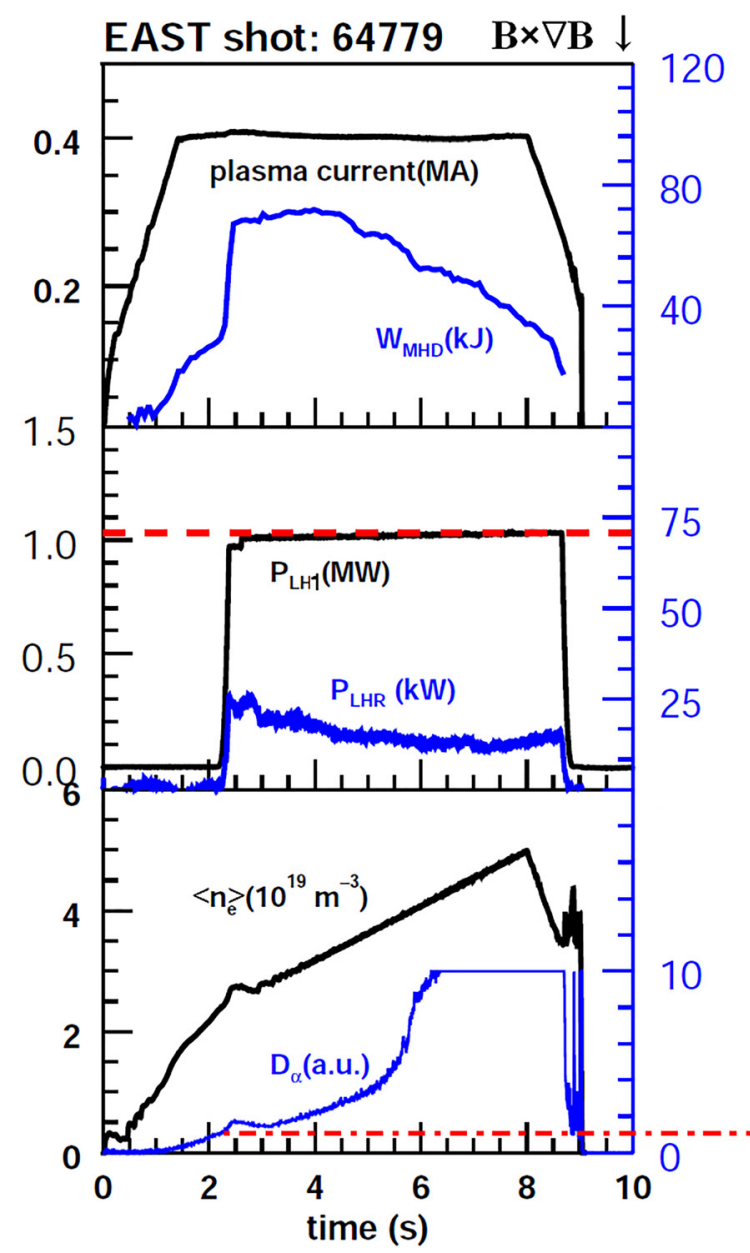

experiment, as manifested by a multi-array and highresolution soft X-ray system measurement.

\section{EDGE PLASMA CONDITIONS AT THE L-H TRANSITIONS}

\section{A. The impurity levels and edge neutral particles}

Plasma conditions either in the edge or the scrape-off layer (SOL) are expected to be relevant to $\mathrm{L}-\mathrm{H}$ transition physics. ${ }^{12}$ In our experiment, the comparison of power threshold with respect to the $\nabla B$ drift direction was carried out among different discharges. Therefore, the edge plasma conditions, especially the edge impurity levels and neutral particles, are analyzed in this section.

The spectroscopic diagnostic for detecting the influx of impurity at the tungsten divertor region has been utilized. ${ }^{24}$ The line emissions intensity of tungsten (W), oxygen (O), nitrogen $(\mathrm{N})$, lithium $(\mathrm{Li})$, and carbon $(\mathrm{C})$, normalized to the D Balmer line $\left(\mathrm{D}_{\delta}, 410.06 \mathrm{~nm}\right)$ measured by the divertor spectroscopy versus loss powers across the separatrix, $P_{\text {loss }}$, are shown in Fig. 6, with respect to two field directions, which are averaged over a time interval of $10 \mathrm{~ms}$ in the Lmode phase just prior to the $\mathrm{L}-\mathrm{H}$ transition. A slight increase in $P_{\text {loss }}$ is found with increasing impurities levels, especially with respect to the $\nabla B$ drift away from the primary X-point $(B \times \nabla B \downarrow)$. This may result in the scattering of $P_{\text {loss }}$ in the

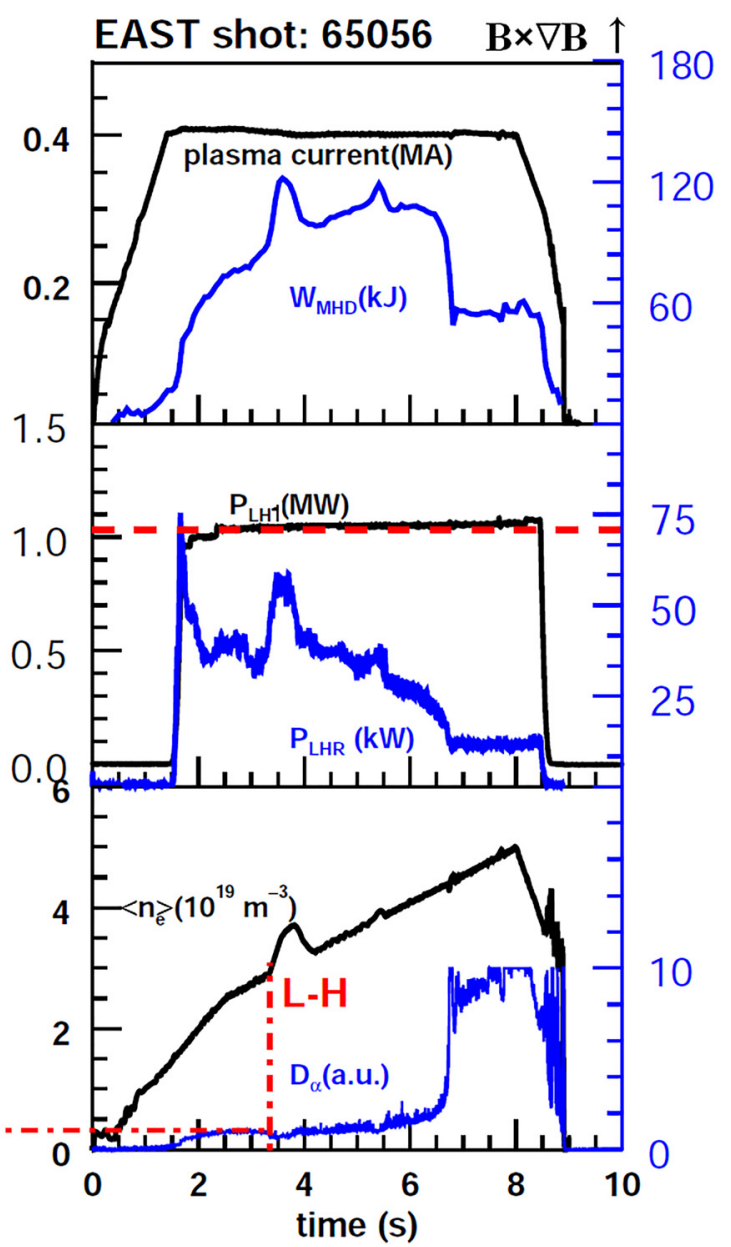

FIG. 4. Density scan experiments with constant input heating power, matched plasma shapes, and $I_{\mathrm{P}} / B_{\mathrm{T}}$ pairs for two field directions, respectively. Transition only occurs for the $\nabla B$ drift towards the primary X-point $(B \times \nabla B \uparrow)$. 

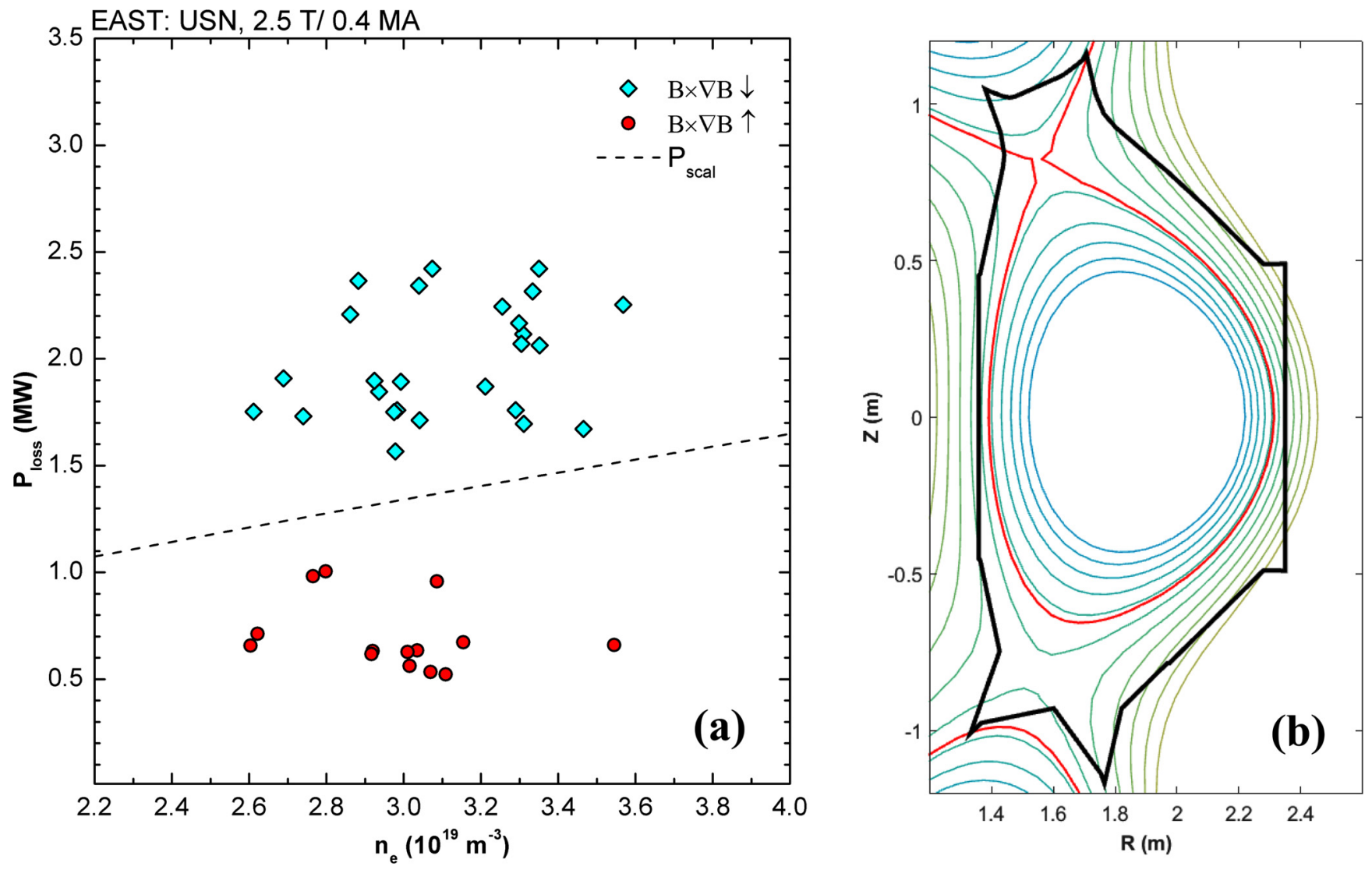

FIG. 5. (a) Experimental power threshold just prior to the L-H transition (L-modes) as a function of line-averaged electron density $\left\langle n_{\mathrm{e}}\right\rangle$ with $I_{\mathrm{P}} / B_{\mathrm{T}}$ pairs and upper single null configuration at different directions of the magnetic field. The edge safety factor, $q_{95}$, and the plasma surface area, $S$, are about 7.0 and 39.0 , respectively. The red solid circles are run for $B \times \nabla B \uparrow$ and the cyan solid diamonds are run for $B \times \nabla B \downarrow$. (b) Magnetic configuration of the shots selected.

experiments. However, it is hard to obtain the quantity of these impurity densities due to lack of divertor diagnostics. On the other hand, with improved wall conditioning as mentioned above, the impurity levels, e.g., oxygen $(\mathrm{O})$, nitrogen $(\mathrm{N})$, carbon $(\mathrm{C})$, and Ferrum $(\mathrm{Fe})$, are all suppressed effectively when compared with that without wall conditioning. As can be seen, similar impurity levels are shown between different $\nabla B$ drift directions. This reveals that there are other variables beyond the impurity that affect the L-H power threshold in our experiments. Note that the line emissions of impurity levels inside the pedestal region measured by a fast-time-response extreme ultraviolet ${ }^{25}$ are also similar, which is not shown here.

The importance of edge neutral particles or recycling to the L-H transition has been realized for a long time. ${ }^{6,10,21,26-31}$ In our experiments, a remarkable result is revealed that the divertor $\mathrm{D} \alpha$ emission is strongly reduced for discharges with the $\nabla B$ drift towards primary X-point than that away from it. This can be clearly seen in Figs. 2 and 4 , that the divertor $\mathrm{D} \alpha$ emission just prior to the $\mathrm{L}-\mathrm{H}$ transition (as evidenced by the red dashed lines in the $\mathrm{D} \alpha$ trace) is lower for the $\nabla B$ drift towards the primary X-point, compared with the $\nabla B$ drift away direction, for discharges with similar target conditions. Statistical analysis of the divertor $\mathrm{D} \alpha$ emission just before the $\mathrm{L}-\mathrm{H}$ transitions is performed for the discharges as mentioned in Fig. 7. Variation of $P_{\text {loss }}$ with the density normalized Da emission at various locations in the vicinity of: (a) the outer strike point, (b) the inner strike point, and (c) baffle at the high field side are plotted in Fig. 7 for two sets of toroidal magnetic field directions, respectively. The lines of sight of the measurement are shown in Fig. 1. As can be seen, the divertor $\mathrm{D} \alpha$ emission is reduced significantly, where a factor of $\sim 2$ is observed, for the $\nabla B$ drift towards the primary X-point $(B \times \nabla B \uparrow)$, compared with that for the $\nabla B$ drift away from the primary $\mathrm{X}$ point $(B \times \nabla B \downarrow)$. A reduced power threshold is found with a lower divertor $\mathrm{D} \alpha$ emission level. The divertor $\mathrm{D} \alpha$ magnitude mainly depends on the Balmer- $\alpha(n=3 \rightarrow 2)$ line emission, which is proportional to $n_{0} n_{\mathrm{e}} f\left(T_{\mathrm{e}}\right)$, where $n_{0}$ is the local neutral particle density, $n_{\mathrm{e}}$ is the local electron density, and $f\left(T_{\mathrm{e}}\right)$ is the rate coefficient dependent on electron temperature, $T_{\mathrm{e}}$. Previous estimation of neutral density in edge plasma simulated by FRANTIC, the 1.5-D fluid transport code, found that a flux-averaged neutral density profile qualitatively depends on the integral $\mathrm{D} \alpha$ emission intensity. ${ }^{32}$ These findings may suggest that there are underlying physics behind the edge neutral particles that affect the L-H transition.

\section{B. The SOL parallel flow measured by the probes}

The ion drift direction affects the plasma flow along field lines in SOL. Measurements of the SOL parallel plasma flow, mainly for low-confinement (L-mode) plasmas (JT60U, ${ }^{33}$ DIII-D, ${ }^{34}$ JET, ${ }^{35}$ ASDEX-Upgrade, ${ }^{36}$ and $\mathrm{TCV}^{37}$ ) clearly indicate that there is a tendency for the plasma to flow along field lines in the co-current direction in SOL on 


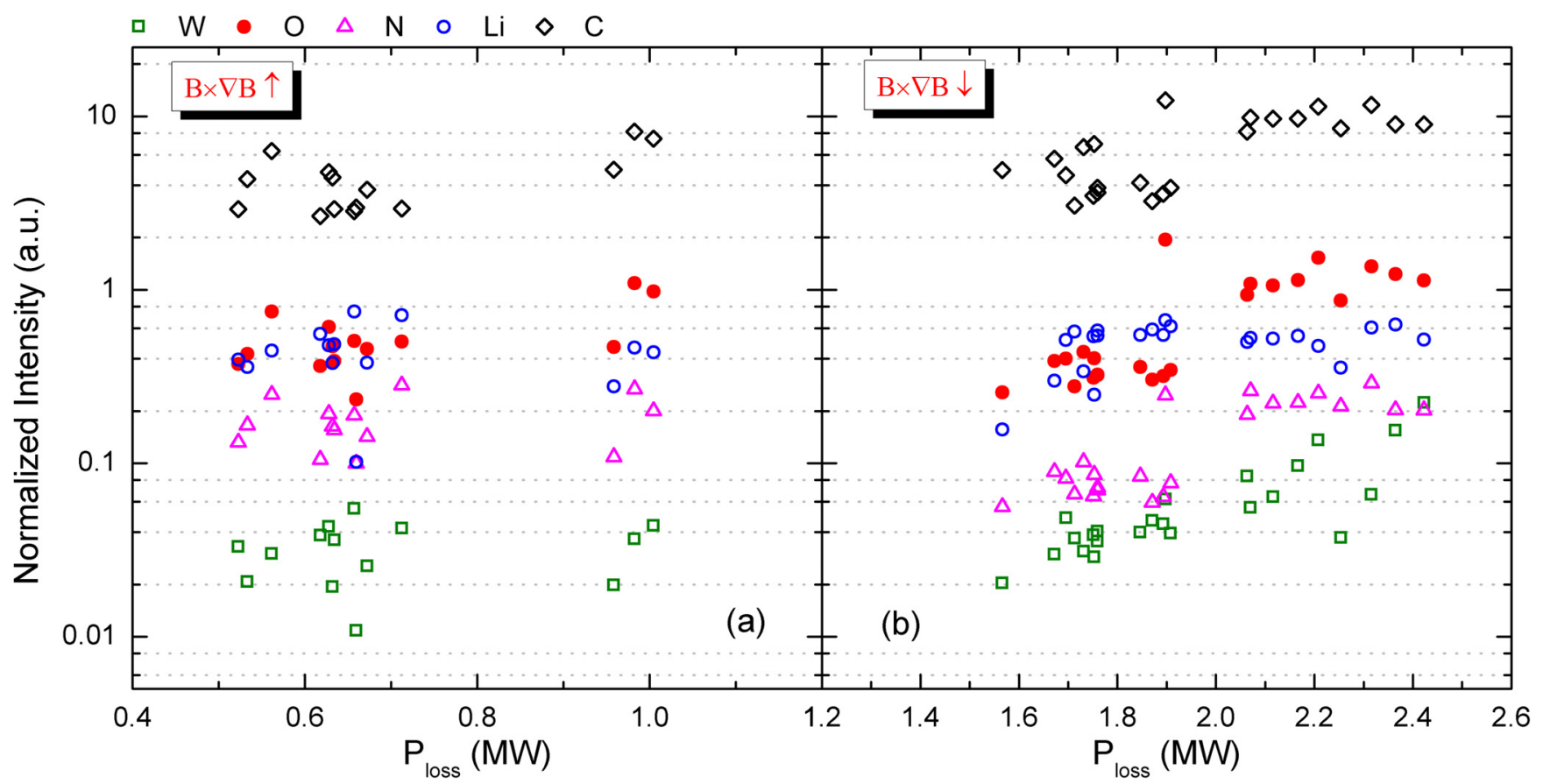

FIG. 6. Comparison of impurity levels, e.g., tungsten (W), oxygen $(\mathrm{O})$, nitrogen $(\mathrm{N})$, lithium ( $\mathrm{Li})$, and carbon $(\mathrm{C})$, just prior to the L-H transition (L-modes) with discharges in different sets of field direction: (a) $B \times \nabla B \uparrow$ and (b) $B \times \nabla B \downarrow$. Note that the intensity is not in absolute quantity.

the low field side near the midplane. These flows tend to reverse when the field is reversed. Recent experiments in Alcator C-Mod indicate that topology-dependent flow boundary conditions may play a role in the sensitivity of the L-H power threshold to the X-point location. ${ }^{38}$ In EAST, the SOL parallel flow has been analyzed, suggests a critical role of the Pfirsch-Schlüter (PS) flow as one of the most flowdriving mechanisms. ${ }^{39-42}$ However, previous results are mainly achieved under the carbon wall divertor.

In the recent experiment of EAST, the divertor particle flux, which is directly associated with SOL parallel flow, can be readily determined from the ion saturation current measurements by the newly upgraded triple Langmuir probe with a high time resolution. ${ }^{43}$ The ion saturation current represents the particle flux as $\Gamma=n_{\mathrm{t}} C_{\mathrm{s}}=j_{\mathrm{s}} / \mathrm{e}=6.24$ $\times 10^{22} j_{\mathrm{s}}\left(\mathrm{A} \mathrm{cm}^{-2}\right)$, where $n_{t}$ and $C_{\mathrm{s}}$ are the electron density and ion sound speed at the target, respectively. Here, a calculation for the divertor particle flux is not available due to the damage of probe head in our experiment. Instead, a comparison of two shots achieved by 1.3-1.4 MW of the $4.6 \mathrm{GHz}$ LHCD run in the USN configuration with the ITER-like tungsten divertor in the 2015 experimental campaign at similar target plasma conditions $\left(\left\langle n_{\mathrm{e}}\right\rangle \sim 2.3\right.$ $\left.\times 10^{19} \mathrm{~m}^{-3}, I_{\mathrm{P}}=0.4 \mathrm{MA}\right)$ was carried out, as shown in Fig. 8. For the $\nabla B$ drift away from the primary X-point (shot 60107, $B \times \nabla B \downarrow$ ), the peak particle flux at the outer target is significantly higher than that at the inner target, with a ratio of the peak particle flux at $0.2-0.3$ between the inner and outer target. In contrast, for the $\nabla B$ drift towards the primary X-point (shot 59972, $B \times \nabla B \uparrow$ ), this asymmetry is considerably mitigated, with a ratio of the peak particle flux at $0.3-0.5$ between the inner and outer target, where an increase in the peak particle flux is found at the lower outer target when the field is reversed.
Furthermore, the SOL plasma parameters are directly measured by the Langmuir probe array at the outer midplane in the USN plasma for the $\nabla B$ drift towards the primary $\mathrm{X}$-point (shot 65061, $B \times \nabla B \uparrow$ ) and in the recent experiment for the $\nabla B$ drift away from the primary X-point (shot 66354 , $B \times \nabla B \downarrow$ ), respectively. The Langmuir probe is composed of a four-tip probe array, a pair of Mach probes, and a triple axis magnetic sensor, to provide the time-dependent measurements of electron density, electron temperature, and parallel ion flow velocities simultaneously, as shown in Fig. 9. The electron temperature is calculated as $T_{\mathrm{e}}=\left(\phi_{+}-\phi_{\mathrm{f}}\right) /$ $\ln 2$, where $\phi_{+}$is the potential measured by the positively biased tip, and, $\phi_{\mathrm{f}}=\left(\phi_{\mathrm{f} 1}+\phi_{\mathrm{f} 2}\right) / 2$, is approximately the floating potential at the midpoint of $\phi_{\mathrm{f} 1}$ and $\phi_{\mathrm{f} 2}$. The two floating potentials are poloidally separated by $\mathrm{dp}=6 \mathrm{~mm}$. The electron density is estimated as $n_{\mathrm{e}}=I_{\mathrm{s}} /\left(0.5 \mathrm{e} A_{\mathrm{eff}} C_{\mathrm{s}}\right)$, where $C_{\mathrm{s}}=\left(2 T_{\mathrm{e}} / m_{\mathrm{i}}\right)^{1 / 2}$ is the sound speed, $A_{\mathrm{eff}}$ is the effective collecting area of the tip, and $\mathrm{e}=1.602 \times 10^{19} \mathrm{C}$. The Mach number and the parallel flow velocity are calculated by using Hutchinson's formula ${ }^{44}$ as $M_{\|}=0.4 \ln \left(I_{\text {up }} / I_{\text {down }}\right)$ and $V_{\|}=M_{\|} C_{\mathrm{s}}$, where $I_{\text {up }}$ and $I_{\text {down }}$ are the ion saturation current densities on each side of Mach probes.

The measurement is carried out at $\sim 50 \mathrm{~ms}$ before the $\mathrm{L}-\mathrm{H}$ transition for the $\nabla B$ drift towards the primary X-point (shot 65061), with plasma conditions at $\left\langle n_{\mathrm{e}}\right\rangle=3.3 \times 10^{19}$ $\mathrm{m}^{-3}, I_{\mathrm{P}}=0.4 \mathrm{MA}$, and $B_{\mathrm{T}}=2.5 \mathrm{~T}$, achieved by $0.95 \mathrm{MW}$ 4.6 GHz LHCD power, as shown in Fig. 10 (left panels). For comparison, recently, measurement has been taken into the SOL of USN plasma for the $\nabla B$ drift away from the primary $\mathrm{X}$-point (shot 66354), as shown in Fig. 10 (right panels). During the probe measurement, plasma conditions are set at $\left\langle n_{\mathrm{e}}\right\rangle=3.6 \times 10^{19} \mathrm{~m}^{-3}, I_{\mathrm{P}}=0.45 \mathrm{MA}$, and $B_{\mathrm{T}}=2.4 \mathrm{~T}$, achieved by $0.98 \mathrm{MW} 4.6 \mathrm{GHz}$ LHCD as well as $0.58 \mathrm{MW}$ $2.45 \mathrm{GHz} \mathrm{LHCD}$ power, and the plasma remains at the 

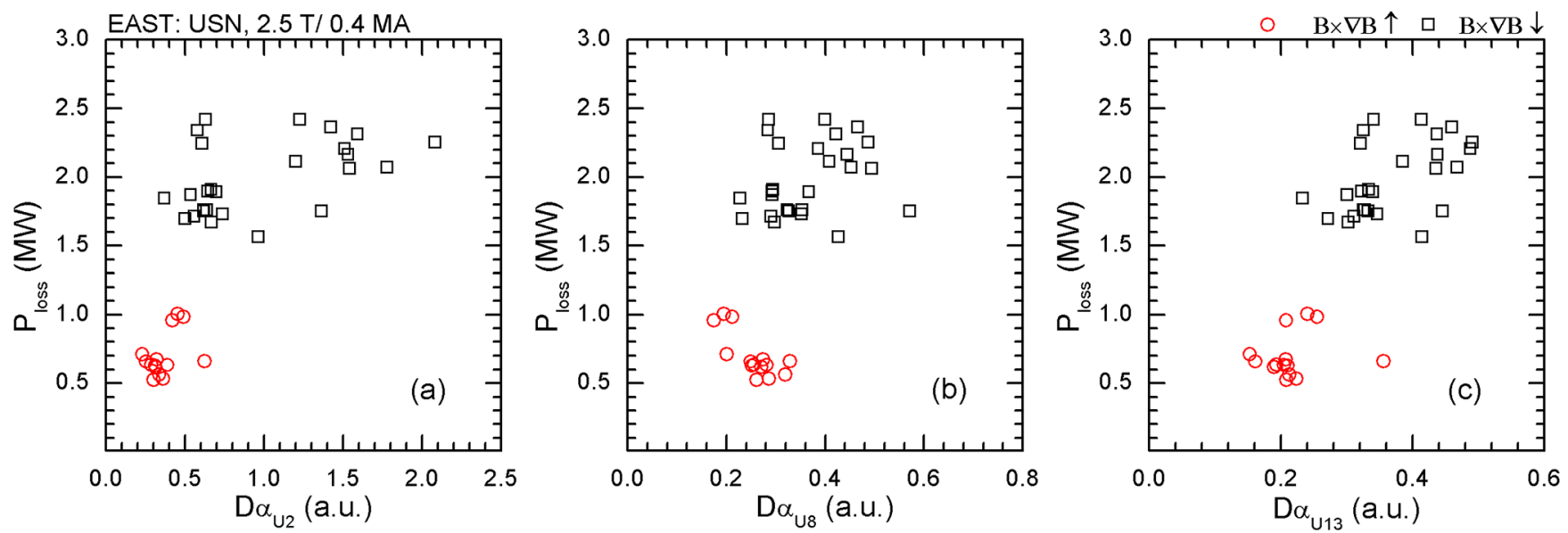

FIG. 7. Variation of $P_{\text {loss }}$ with the density normalized Da emission just prior to the L-H transition (L-modes) at various locations in the vicinity of: (a) the outer strike point, (b) the inner strike point, and (c) baffle at the high field side, for two sets of toroidal magnetic field direction, respectively. The lines of sight of the measurement are shown in Fig. 1.

L-mode. Figures 10(a) and 10(e) show the probe scanning positions, where the probe reached a radial position at $\sim 1 \mathrm{~cm}$ outside the separatrix and stayed there for $\sim 200 \mathrm{~ms}$. The raw signals of the ion saturation current, $I_{\mathrm{s}}$ and its timefrequency power spectrum are shown in Figs. 10(b) and 10(c) and Figs. 10(f) and 10(g), respectively. Broadband fluctuations (mainly in $0-200 \mathrm{kHz}$ ) are seen for the two set of field directions. Significant turbulence-driven outward particle flux, $\Gamma=\left\langle\delta v_{\mathrm{r}} \delta n_{\mathrm{e}}\right\rangle$, is directly observed by the fourtip probe array, as shown in Figs. 10(d) and 10(h). Here, the radial advection velocity fluctuation is estimated as $\delta v_{\mathrm{r}}=\delta E_{\mathrm{p}} / B=\left(\delta \phi_{\mathrm{f} 1}-\delta \phi_{\mathrm{f} 2}\right) /(\mathrm{dp} B)$, where $\delta$ represents fluctuation components with frequencies above $5 \mathrm{kHz}$ where the turbulence dominates the spectrum.
Profiles of electron density, $n_{\mathrm{e}}$, temperature, $T_{\mathrm{e}}$, and parallel flow velocity, $V_{\|}$for the two set of field directions, are shown in Fig. 11. The measured density profile is broad, almost flat, in the near SOL close to separatrix for the $\nabla B$ drift away from the primary X-point (shot 66354, $B \times \nabla B \downarrow$ ), whereas, the density profile decays exponentially from the separatrix towards the wall for the $\nabla B$ drift towards the primary X-point (shot 65061, $B \times \nabla B \uparrow$ ), as shown in Fig. 11(a). Therefore, a formation of a "shoulder" in the SOL density profile can be obtained by reversing the toroidal field direction in this experiment. Note that, there are spikes in the density profiles, and a drop of the temperature occurred simultaneously, which are caused by the supersonic molecular beam injection (SMBI), as indicated in the figure. Figure 11(b)
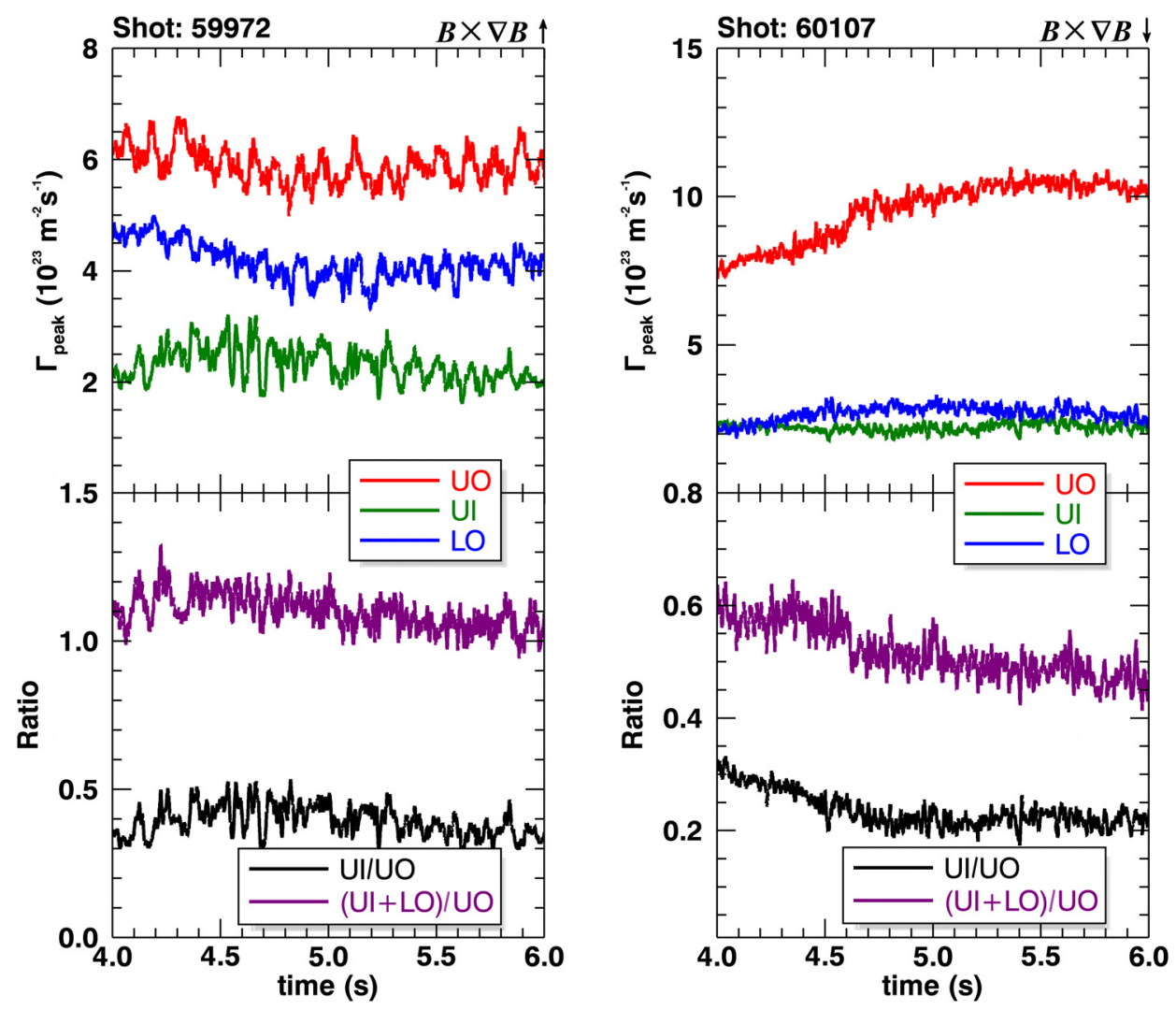

FIG. 8. Comparison of peak particle fluxes $\left(\Gamma_{\text {peak }}\right)$ between upper outer (UO), upper inner (UI), and lower outer (LO) divertor targets for two field directions. 
Top view

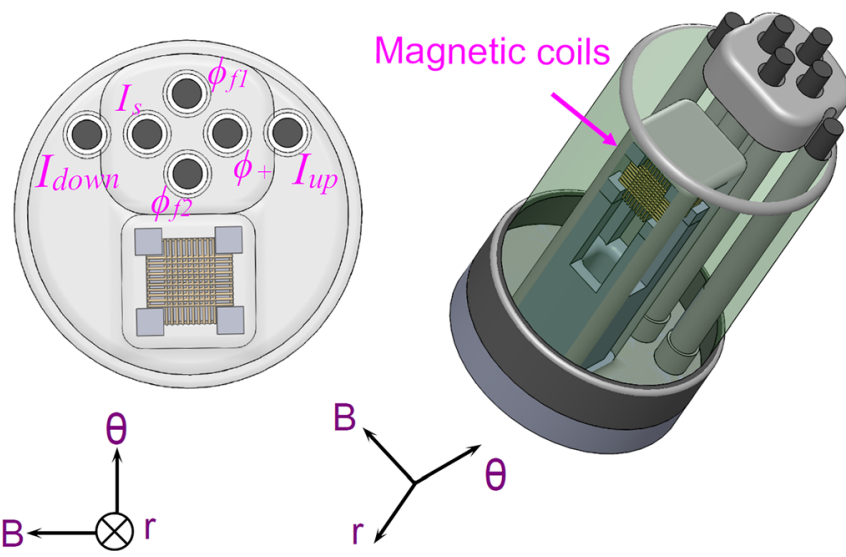

FIG. 9. Layout of the Langmuir probe array.

shows a higher electron temperature for the $\nabla B$ drift away from the primary X-point, which mainly caused by the additional heating of the $2.45 \mathrm{GHz}$ LHCD power, as mentioned before. Interestingly, a significant change of the SOL parallel flow velocity can be observed directly measured by Mach probes when reversing the toroidal field direction. As shown in Fig. 11(c), a velocity of the SOL parallel flow $\left(V_{\|}\right)$evaluated $\sim-10 \mathrm{~km} / \mathrm{s}$, is observed at $\sim 1.0 \mathrm{~cm}$ outside the separatrix, directing towards the upper divertor (shot 65061,
$B \times \nabla B \uparrow)$. In contrast, a strong SOL flow also directed towards the upper divertor, is observed with a velocity $V_{\|}$ $\sim-40 \mathrm{~km} / \mathrm{s}$ (shot $66354, B \times \nabla B \downarrow)$, which is much stronger than that for the $\nabla B$ drift towards the primary X-point. This different amplitude of the SOL parallel flow velocity may cause the asymmetry of divertor particle flux, as mentioned before, and indicate that the SOL parallel flow may play a critical role in the transition physics.

The SOL parallel flow may correlate with the edge density gradient, as the formation of a density "shoulder" can be obtained when reversing the field direction. The influence on the density profile is further evidenced by dedicated experiments with matched plasma shapes and divertor configuration, $I_{\mathrm{P}} / B_{\mathrm{T}}$ pairs, and the same core line-averaged density $\left\langle n_{\mathrm{e}}\right\rangle \sim 3 \times 10^{19} \mathrm{~m}^{-3}$ for both field directions. Figure 12 shows the edge plasma density profiles in a time of $20 \mathrm{~ms}$ just before the L-H transitions, measured by the reflectometry in the vicinity of the separatrix and fitted by using the modified tanhfit function. ${ }^{45}$ A reduced SOL density and thus steeper density gradient inside the separatrix is revealed for the ion $\nabla B$ drift towards the primary X-point. Note that a lower edge neutral particle density is demonstrated for the ion $\nabla B$ drift towards the primary X-point, as mentioned previously. These neutral particles play a role in the plasma fuelling which dominates at the edge and SOL region. Thus, a lower edge neutral particle density may result in a reduced
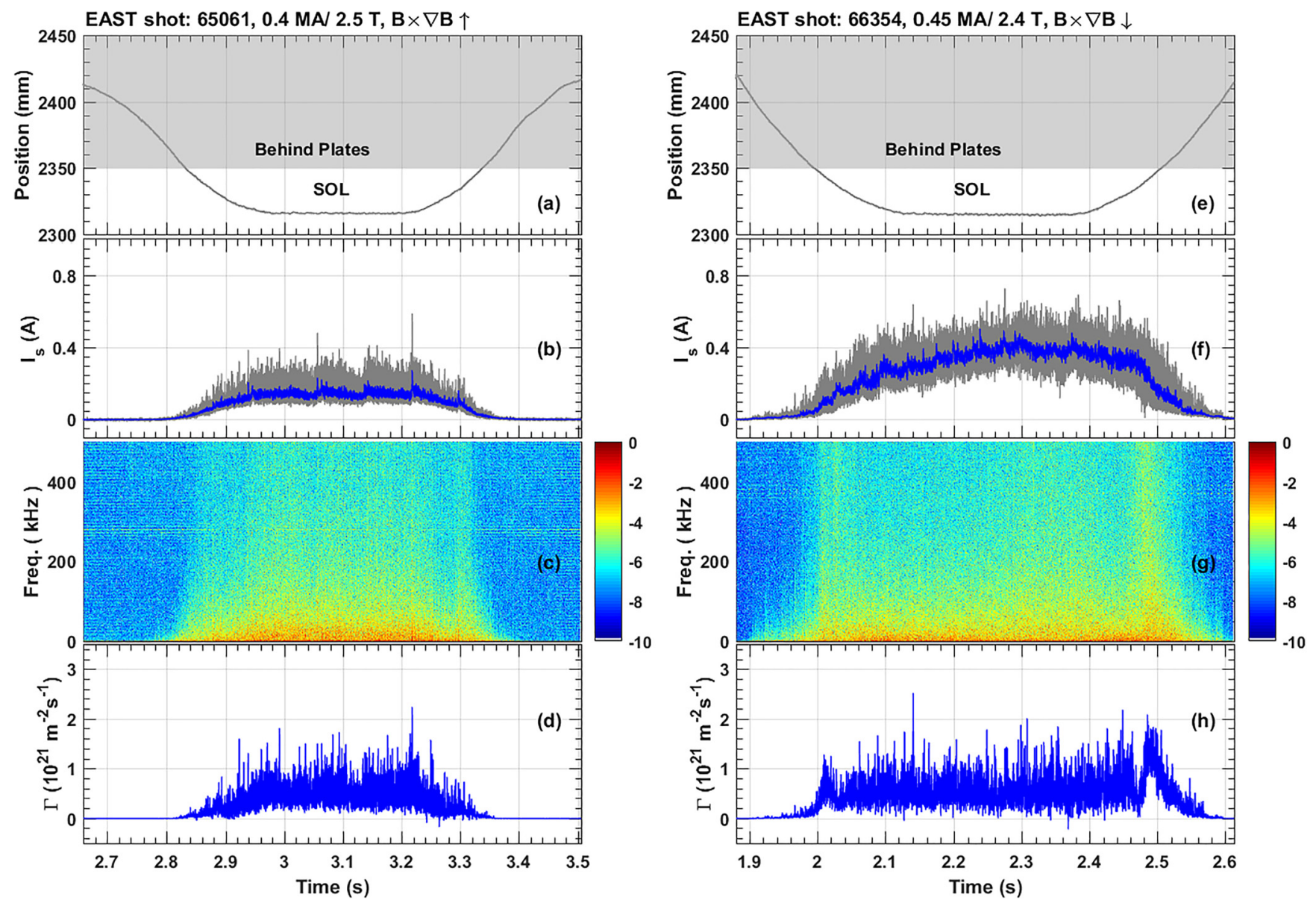

FIG. 10. Time evolution of probe measurements for the two set of field directions: (a) and (e) probe scanning position, (b) and (f) ion saturation current, $I_{\mathrm{s}}$, (c) and $(\mathrm{g})$ its power spectrum, and $(\mathrm{d})$ and $(\mathrm{h})$ fluctuation-driven particle flux, $\Gamma$. 


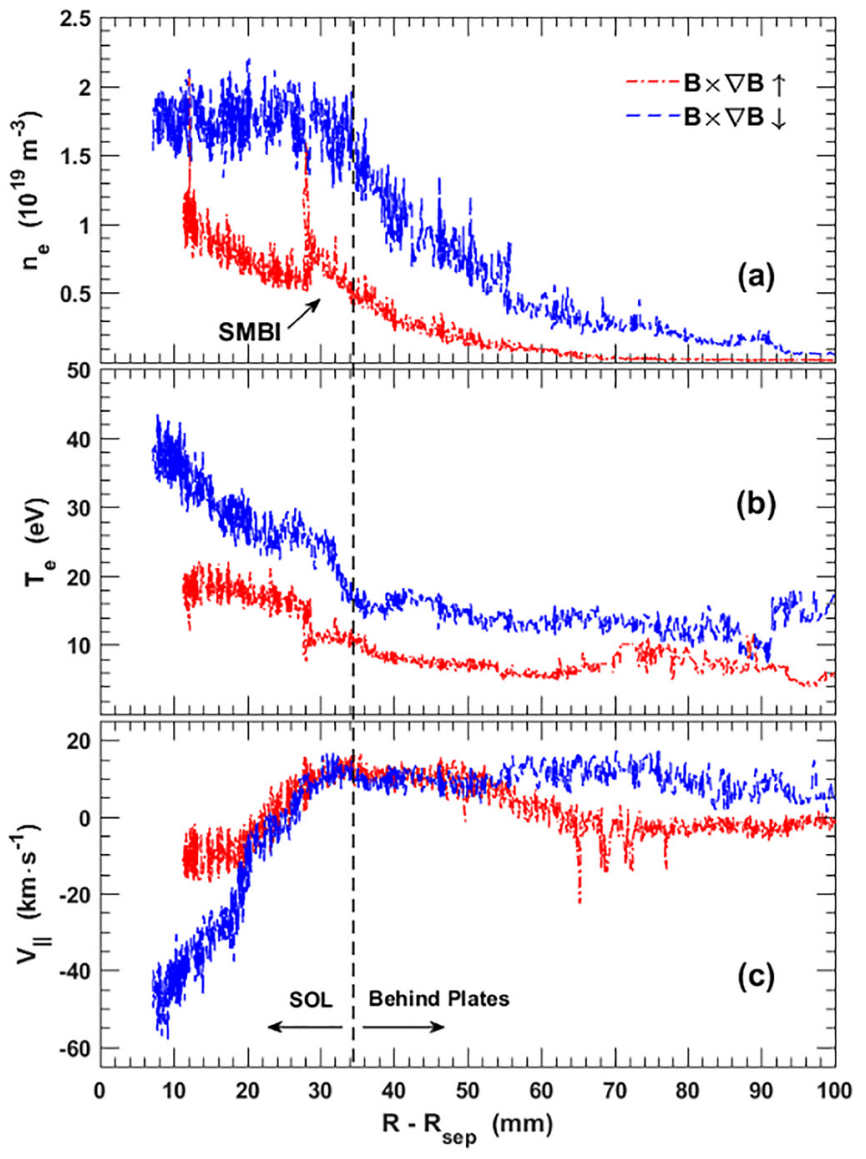

FIG. 11. Profiles of electron density, $n_{\mathrm{e}}$, temperature, $T_{\mathrm{e}}$, and parallel plasma flow, $V_{\|}$measured by a fast reciprocating Langmuir probe on the outer midplane of EAST, for $B \times \nabla B \uparrow$ (red line) and $B \times \nabla B \downarrow$ (blue line), respectively. The arrows indicate when the probe crosses the limiter plates and $\left(R-R_{\text {sep }}\right)$ is the radial distance to the separatrix.

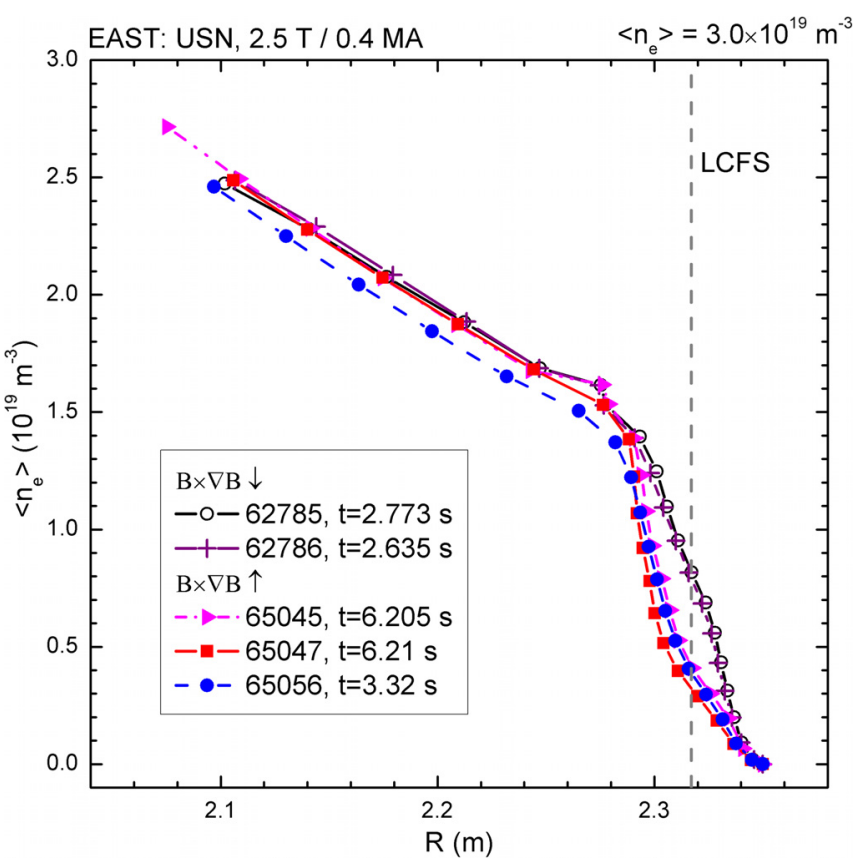

FIG. 12. The edge plasma density profiles just prior to the $\mathrm{L}-\mathrm{H}$ transitions in EAST with matched plasma shapes and divertor configuration, $I_{\mathrm{P}} / B_{\mathrm{T}}$ pairs, and similar core line-averaged density $\left\langle n_{\mathrm{e}}\right\rangle \sim 3 \times 10^{19} \mathrm{~m}^{-3}$ for two sets of field direction.
SOL density. A similar result has been found in ASDEX Upgrade $^{46}$ to explain the lower power threshold in the full tungsten wall versus the all carbon wall, where a much steeper edge density gradient is demonstrated in the $\mathrm{W}$-wall because of the wall reflection. Also in NSTX, ${ }^{47}$ lithium wall coatings have been shown to reduce recycling, coupled with a reduction of the average edge density profile gradient and shifted it radially inwards from the separatrix location.

\section{Discussion: A possible mechanism to the transition threshold}

To illustrate the ion $\nabla B$ drift dependence of the transition threshold, a schematic diagram of the SOL parallel plasma flow primarily based on the probe measurement is shown in Fig. 13. The cases of counter-clockwise $(B \times \nabla B \uparrow)$ and clockwise $(B \times \nabla B \downarrow)$ directions of the field $B_{\mathrm{T}}$ are shown, respectively. As mentioned before, the measured SOL parallel flow on the outer midplane is directed towards the upper divertor for both field directions, as indicated by black arrows. The direction of the PS flow component of the SOL parallel flow depends on the ion $\nabla B$ drift direction, which is directed upwards for $B \times \nabla B \downarrow$ and downwards for $B \times \nabla B \uparrow$, as shown by the green arrows. Furthermore, a significant asymmetry of particle flux, favoring the outer divertor, is observed for $B \times \nabla B \downarrow$ (see Fig. 8). This asymmetry is considerably mitigated when the field is reversed, as manifested by the divertor Langmuir triple probe measurement. The in-out asymmetry pattern is strongly correlated with the fielddependent PS flow direction, suggesting that the SOL flow may play a critical role on the transition threshold. In general, more particles might be recycled as particle flow is enhanced. This, associated with the open divertor geometry, may result in a high neutral particle density for $B \times \nabla B \downarrow$ with strong particle flux flow on the outer divertor target. Note that there are two up-down cryopump systems underneath the outer divertor target, as shown in Fig. 13. The typical Wshaped divertor geometry, as well as the outer located cryopump, can still keep the edge neutral particles at low levels when the particle flux is enhanced at the lower outer divertor target for $B \times \nabla B \uparrow$. Therefore, the field-dependent flow pattern, associated with the special divertor geometries and the cryopumps, cause different edge neutral particle densities as well as edge density profiles, and further affect the transition threshold. These findings point to an important role of the field-dependent SOL parallel flow on the L-H transition.

\section{SUMMARY}

In summary, experiments have been carried out to investigate the effect of ion $\nabla B$ drift on the H-mode power threshold in the USN configuration with the ITER-like tungsten divertor on EAST. A lower power threshold is found for the ion $\nabla B$ drift towards the primary X-point $(B \times \nabla B \uparrow)$, correlated with a lower edge neutral density as well as a steeper edge density gradient, compared with that for the ion $\nabla B$ drift away from the primary X-point $(B \times \nabla B \downarrow)$. In addition, a significant asymmetry of particle flux, favoring the outer divertor, is observed for $B \times \nabla B \downarrow$. This asymmetry is considerably reduced when the field is reversed, as manifested by 


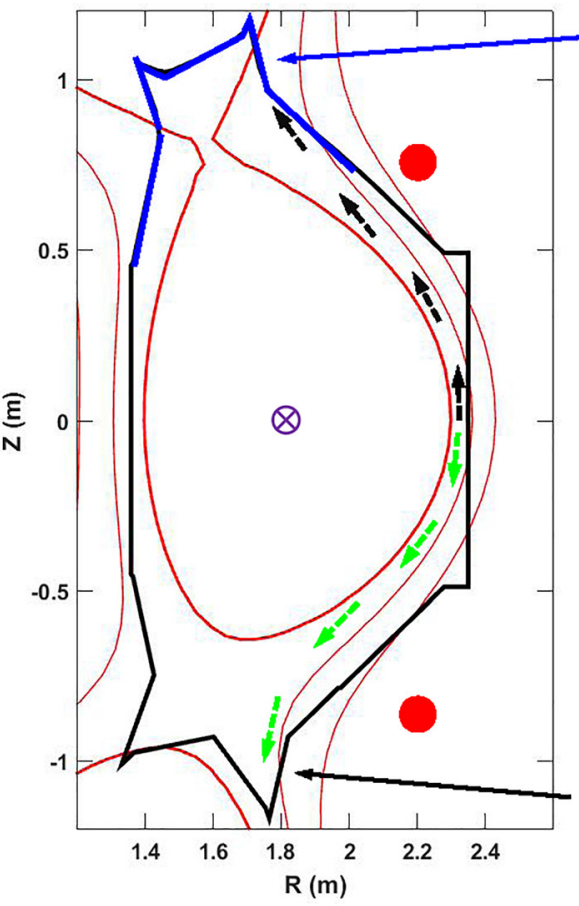

(a) $B \times \nabla B \uparrow$

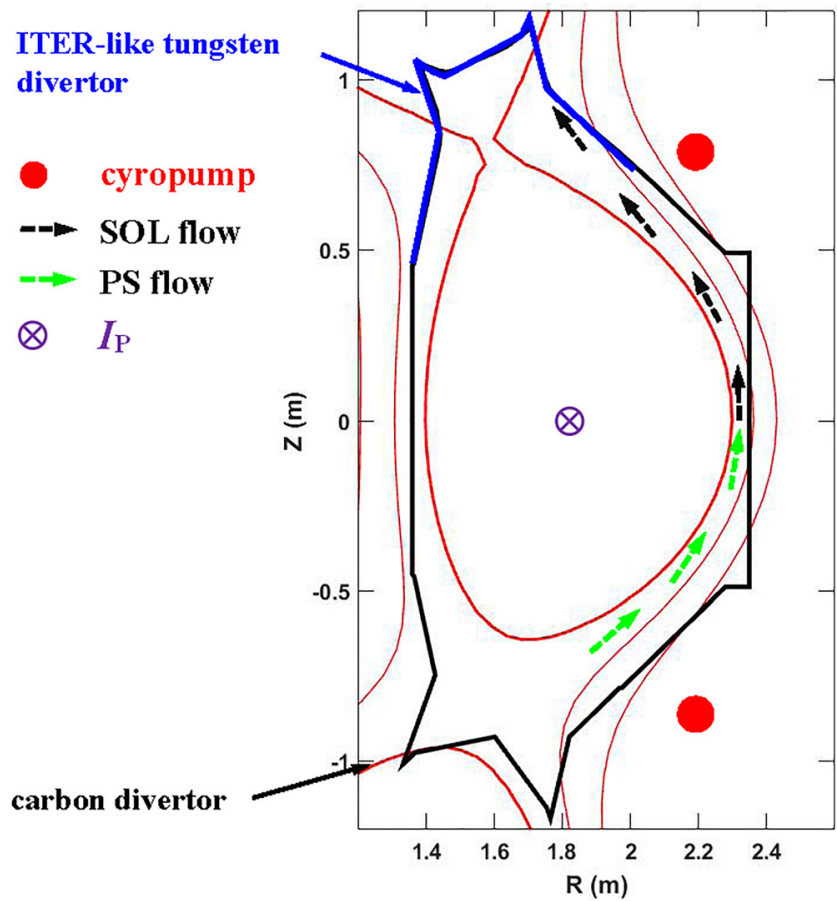

(b) $B \times \nabla B \downarrow$

FIG. 13. Schematic view of parallel plasma flows at the SOL region in the USN configuration for (a) $B \times \nabla B \uparrow$ and (b) $B \times \nabla B \downarrow$.

the divertor Langmuir triple probe as well as a fast reciprocating probe measurement. The direction of the PS flow component of the SOL parallel flow depends on the ion $\nabla B$ drift direction, which is directed upwards for $B \times \nabla B \downarrow$ and downwards for $B \times \nabla B \uparrow$, indicating that the in-out asymmetry may be affected by the field-dependent PS flow. To illustrate the ion $\nabla B$ drift dependence of the transition threshold, a schematic diagram of the SOL parallel plasma flow primarily based on the probe measurement is proposed. These findings suggest that the divertor neutral particle density or recycling, which correlated with the field-dependent SOL flow, plays an important role in the transition physics. Similar results have been found in the Alcator C-Mod, that the poloidal component of the parallel flow always pointing towards the outer divertor in the LFS SOL for the two magnetic configurations. ${ }^{48}$ At C-Mod, the parallel flow shows comparable magnitudes for the two magnetic configurations, whereas it exhibits a considerable asymmetry for the two field directions in USN plasmas on EAST. This different flow pattern may lead to results of the field-dependent power threshold. Note that the flows measured from C-Mod are for Ohmic discharges, and that the probes are not located precisely on the LFS midplane, whereas the flows measured here are from L-mode discharges at the LFS midplane from EAST. Still, it is not clear why the SOL flow is not reversed with reversing field direction, which is different from previous results on EAST under all carbon divertors. ${ }^{39-42}$ This may be related to the up-down asymmetry divertors, in both material and geometry. In this paper, the role of neutral particle density on the L-H transition is qualitatively analyzed using the normalized divertor $\mathrm{D} \alpha$ emission, however, diagnostics for the local $T_{\mathrm{e}}, n_{\mathrm{e}}$ profile in the divertor region are needed. Further experiments dedicated to the understanding of the physics behind the L-H power threshold will be performed in the next experimental campaign on EAST.

\section{ACKNOWLEDGMENTS}

This work was supported by the National Natural Science Foundation of China under Contract Nos. 11422546, 10990212, 10990210, 11321092, and 11105181 and the SRG-HSC Project No. 2015SRG-HSC002, AHNFS under Contract No. 1808085J07, the National Magnetic Confinement Fusion Science Program of China under Contract Nos. 2015GB101000 and 2014GB124006, the China Postdoctoral Science Foundation under Contract No. 2016M602043, and the Sino Danish Center for Education and Research.

${ }^{1}$ F. Wagner, G. Becker, K. Behringer, D. Campbell, A. Eberhagen, W. Engelhardt, G. Fussmann, O. Gehre, J. Gernhardt, G. Vongierke et al., Phys. Rev. Lett. 49, 1408 (1982).

${ }^{2}$ G. S. Xu and X. Q. Wu, Plasma Sci. Technol. 19, 033001 (2017).

${ }^{3}$ Y. R. Martin and T. Takizuka, and ITPA CDBM H-mode Threshold Database Working Group, J. Phys.: Conf. Ser. 123, 012033 (2008).

${ }^{4}$ K. H. Burrell, T. N. Carlstrom, E. J. Doyle, P. Gohil, R. J. Groebner, T. Lehecka, N. C. Luhmann, Jr., H. Matsumoto, T. H. Osborne, W. A. Peebles, and R. Philipona, Phys. Fluids B 2, 1405 (1990).

${ }^{5}$ E. J. Kim and P. H. Diamond, Phys. Rev. Lett. 90, 185006 (2003).

${ }^{6}$ K. C. Shaing and C. T. Hsu, Phys. Plasmas 2, 1801 (1995).

${ }^{7}$ C. F. Maggi, E. Delabie, T. M. Biewer, M. Groth, N. C. Hawkes, M. Lehnen, E. de la Luna, K. McCormick, C. Reux, F. Rimini et al., Nucl. Fusion 54, 023007 (2014).

${ }^{8}$ F. Ryter, S. K. Rathgeber, L. Barrera Orte, M. Bernert, G. D. Conway, R. Fischer, T. Happel, B. Kurzan, R. M. McDermott, A. Scarabosio1 et al., Nucl. Fusion 53, 113003 (2013).

${ }^{9}$ Z. X. Liu, X. Gao, S. C. Liu, S. Y. Ding, T. Y. Xia, T. Zhang, S. B. Zhang, Y. M. Wang, X. Han, J. G. Li et al., Nucl. Fusion 53, 073041 (2013).

${ }^{10}$ F. Wagner, R. Bartiromo, G. Becker, H. S. Bosch, A. Eberhagen, G. Fussmann, O. Gehre, J. Gernhardt, G. V. Gierke, E. Glock et al., Nucl. Fusion 25, 1490 (1985). 
${ }^{11}$ T. N. Carlstrom, R. J. Groebner, C. Fenzi, G. R. McKee, R. A. Moyer, and T. L. Rhodes, Plasma Phys. Controlled Fusion 44, A333 (2002).

${ }^{12}$ B. LaBombard, J. E. Rice, A. E. Hubbard, J. W. Hughes, M. Greenwald, R. S. Granetz, J. H. Irby, Y. Lin, B. Lipschultz, E. S. Marmar et al., Phys. Plasmas 12, 056111 (2005).

${ }^{13}$ J. W. Hughes, A. E. Hubbard, D. A. Mossessian, B. LaBombard, T. M. Biewer, R. S. Granetz, M. Greenwald, I. H. Hutchinson, J. H. Irby, Y. Lin et al., Fusion Sci. Technol. 51, 317 (2007).

${ }^{14}$ R. Maingi, S. M. Kaye, R. E. Bell, T. M. Biewer, C. S. Chang, D. A. Gates, S. P. Gerhardt, J. Hosea, B. P. LeBlanc, H. Meyer et al., Nucl. Fusion 50, 064010 (2010).

${ }^{15}$ H. Meyer, P. G. Carolan, G. D. Conway, G. Cunningham, L. D. Horton, A. Kirk, R. Maingi, F. Ryter, S. Saarelma, J. Schirmer et al., Nucl. Fusion 46, 64 (2006).

${ }^{16}$ F. L. Hinton and G. M. Staebler, Nucl. Fusion 29, 405 (1989).

${ }^{17}$ I. Cziegler, A. E. Hubbard, J. W. Hughes, J. L. Terry, and G. R. Tynan, Phys. Rev. Lett. 118, 105003 (2017).

${ }^{18}$ D. C. McDonald, Y. Andrew, G. T. A. Huysmans, A. Loarte, J. Ongena, J. Rapp, and S. Saarelma, Fusion Sci. Technol. 53, 891 (2008).

${ }^{19}$ B. N. Wan, J. Li, H. Y. Guo, Y. F. Liang, G. S. Xu, L. Wang, X. Z. Gong, and A. Garofalo, for the EAST Team and Collaborators. Nucl. Fusion 55, 104015 (2015).

${ }^{20}$ Z. H. Hu, C. Li, Q. M. Xiao, P. Liu, F. Ding, H. M. Mao, J. Wu, D. Y. Zhao, H. B. Ding, G. N. Luo, and EAST Team. Plasma Sci. Technol. 19, 025502 (2017).

${ }^{21}$ L. Chen, G. S. Xu, A. H. Nielsen, W. Gao, Y. M. Duan, H. Q. Liu, L. Wang, M. H. Li, M. Wang, X. J. Zhang et al., Nucl. Fusion 56, 056013 (2016).

${ }^{22}$ B. Wu, B. L. Hao, R. White, J. F. Wang, Q. Zang, X. F. Han, and C. D. Hu, Plasma Phys. Controlled Fusion 59, 025004 (2017).

${ }^{23}$ H. D. Xu, X. J. Wang, F. K. Liu, J. Zhang, Y. Y. Huang, J. F. Shan, D. J. Wu, H. C. Hu, B. Li, M. H. Li et al., Plasma Sci. Technol. 18, 442 (2016).

${ }^{24}$ H. M. Mao, F. Ding, G. N. Luo, Z. H. Hu, X. H. Chen, F. Xu, Z. S. Yang, J. B. Chen, L. Wang, R. Ding et al., Rev. Sci. Instrum. 88, 043502 (2017).

${ }^{25}$ L. Zhang, S. Morita, Z. Xu, Z. W. Wu, P. F. Zhang, C. R. Wu, W. Gao, T. Ohishi, M. Goto, J. S. Shen et al., Rev. Sci. Instrum. 86, 123509 (2015).

${ }^{26}$ R. J. Fonck, M. Bell, K. Bol, R. Budny, P. Couture, D. Darrow, H. Dylla, R. Goldston, B. Grek, R. Hawryluk et al., J. Nucl. Mater. 128-129, 330-339 (1984).

${ }^{27}$ S.-I. Itoh and K. Itoh, Nucl. Fusion 29, 1031 (1989).

${ }^{28}$ B. A. Carreras, P. H. Diamond, and G. Vetoulix, Phys. Plasmas 3, 4106 (1996).

${ }^{29}$ J. A. Snipes, R. L. Boivin, C. Christensen, C. Fiore, D. Garnier, J. Goetz, S. N. Golovato, M. Graf, R. S. Granetz, M. Greenwald et al., Phys. Plasmas 3, 1992 (1996).

${ }^{30}$ L. W. Owen, B. A. Carreras, R. Maingi, P. K. Mioduszewski, T. N. Carlstrom, and R. J. Groebner, Plasma Phys. Controlled Fusion 40, 717 (1998).
${ }^{31}$ K. Tsuchiya, T. Fukuda, Y. Kamada, H. Takenaga, T. Takizuka, M. Mori, T. Fujita, and the JT-60 Team. Plasma Phys. Controlled Fusion 40, 713 (1998).

${ }^{32}$ L. Zhang, G. S. Xu, S. Y. Ding, W. Gao, Z. W. Wu, Y. J. Chen, J. Huang, X. J. Liu, Q. Zang, J. F. Chang et al., Plasma Sci. Technol. 13, 431 (2011).

${ }^{33}$ N. Asakura, H. Takenaga, S. Sakurai, G. D. Porter, T. D. Rognlien, M. E. Rensink, K. Shimizu, S. Higashijima, and H. Kubo, Nucl. Fusion 44, 503 (2004).

${ }^{34}$ J. A. Boedo, R. Lehmer, R. A. Moyer, J. G. Watkins, G. D. Porter, T. E. Evans, A. W. Leonard, and M. J. Schaffer, J. Nucl. Mater. 266, 783 (1999).

${ }^{35}$ A. V. Chankin, D. J. Campbell, S. Clement, S. J. Davies, L. D. Horton, J. Lingertat, A. Loarte, G. F. Matthews, R. D. Monk, R. Reichle et al., Plasma Phys. Controlled Fusion 38, 1579 (1996).

${ }^{36}$ M. Faitsch, B. Sieglin, T. Eich, H. J. Sun, and A. Herrmann, and the ASDEX Upgrade Team. Plasma Phys. Controlled Fusion 57, 075005 (2015).

${ }^{37}$ R. A. Pitts, J. Horacek, W. Fundamenski, O. E. Garcia, A. H. Nielsen, M. Wischmeier, V. Naulin, and J. Juul Rasmussen, J. Nucl. Mater. 363-365, 505-510 (2007).

${ }^{38}$ B. LaBombard, J. E. Rice, A. E. Hubbard, J. W. Hughes, M. Greenwald, J. Irby, Y. Lin, B. Lipschultz, E. S. Marmar, C. S. Pitcher et al., Nucl. Fusion 44, 1047-1066 (2004).

${ }^{39}$ G. S. Xu, V. Naulin, B. N. Wan, H. Y. Guo, W. Zhang, J. F. Chang, N. Yan, S. Y. Ding, L. Zhang, L. Wang et al., Plasma Sci. Technol. 13, 397 (2011).

${ }^{40}$ N. Yan, A. H. Nielsen, G. S. Xu, V. Naulin, J. J. Rasmussen, J. Madsen, H. Q. Wang, S. C. Liu, W. Zhang, L. Wang, and B. N. Wan, Plasma Phys. Controlled Fusion 55, 115007 (2013).

${ }^{41}$ G. S. Xu, H. Q. Wang, M. Xu, B. N. Wan, H. Y. Guo, P. H. Diamond, G. R. Tynan, R. Chen, N. Yan, D. F. Kong et al., Nucl. Fusion 54, 103002 (2014).

${ }^{42}$ J. B. Liu, H. Y. Guo, L. Wang, G. S. Xu, T. Y. Xia, S. C. Liu, X. Q. Xu, J. Li, L. Chen, N. Yan et al., Nucl. Fusion 56, 066006 (2016).

${ }^{43}$ J. C. Xu, L. Wang, G. S. Xu, G. N. Luo, D. M. Yao, Q. Li, L. Cao, L. Chen, W. Zhang, S. C. Liu et al., Rev. Sci. Instrum. 87, 083504 (2016).

${ }^{44}$ I. H. Hutchinson, Phys. Rev. A 37, 4358 (1988).

${ }^{45}$ R. J. Groebner, D. R. Baker, K. H. Burrell, T. N. Carlstrom, J. R. Ferron, P. Gohil, L. L. Lao, T. H. Osborne, D. M. Thomas, and W. P. West, Nucl. Fusion 41, 1789 (2001).

${ }^{46}$ L. M. Shao, E. Wolfrum, F. Ryter, G. Birkenmeier, F. M. Laggner, E. Viezzer, R. Fischer, M. Willensdorfer, B. Kurzan, and T. Lunt, and the ASDEX Upgrade Team. Plasma Phys. Controlled Fusion 58, 025004 (2016).

${ }^{47}$ R. Maingi, D. P. Boyle, J. M. Canik, S. M. Kaye, C. H. Skinner, J. P. Allain, M. G. Bell, R. E. Bell, S. P. Gerhardt, T. K. Gray et al., Nucl. Fusion 52, 083001 (2012).

${ }^{48}$ N. Smick, B. LaBombard, and I. H. Hutchinson, Nucl. Fusion 53, 023001 (2013). 